\title{
Calibration of Beta-Particle-Emitting Ophthalmic Applicators
}

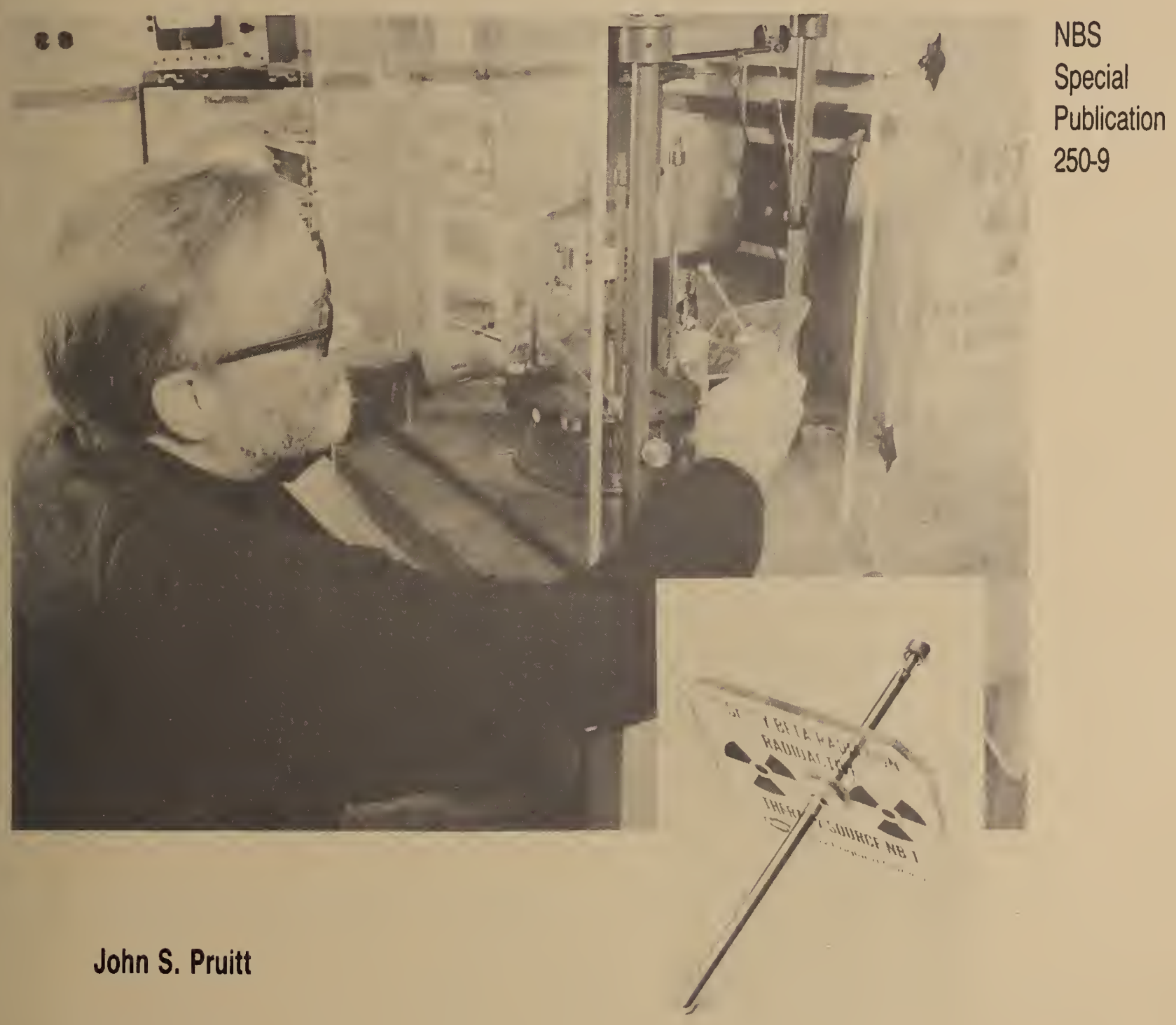

U.S. Department of Commerce

National Bureau of Standards 


\title{
Center for Radiation Research
}

The Center for Radiation Research is a major component of the National Measurement Laboratory in the National Bureau of Standards. The Center provides the Nation with standards and measurement services for ionizing radiation and for ultraviolet, visible, and infrared radiation; coordinates and furnishes essential support to the National Measurement Support System.for ionizing radiation; conducts research in radiation related fields to develop improved radiation me asurement methodology; and generates, compiles, and critically evaluates data to meet major national needs. The Center consists of five Divisions and one Group.

\section{Atomic and Plasma Radiation Division}

Carries out basic theoretical and experimental research into the spectroscopic and radiative properties of atoms and highly ionized species; develops well-defined atomic radiation sources as radiometric or wavelength standards; develops new measurement techniques and methods for spectral analysis and plasma properties; and collects, compiles, and critically evaluates spectroscopic data. The Division consists of the following Groups:

\section{Radiation Physics Division}

Provides the central national basis for the measurement of far ultraviolet, soft $x-r a y$, and electron radiation; develops and disseminates radiation standards, measurement services, and data for for these radiations; conducts theoretical and experimental research with electron, laser, ultraviolet, and soft $x-r$ ay $r$ adiation for measurement applications; determines fundamental mechanisms of electron and photon interactions with matter; and develops advanced electron- and photon-based measurement techiques. The Division consists of the following Groups:
- Atomic Spectroscopy

- Atomic Radiation Data

- Plasma Radiation

\section{Radiometric Physics Division}

\author{
Provides national measurement standards and support services for ultra- \\ violet, visible, and infrared radiation; provides standards dissemination \\ and measurement quality assurance services; conducts research in optical \\ radiation, pyrometry, photometry, and quantum radiometry; and develops \\ spectroradiometric and spectrophotometric standards and calibration \\ procedures. The Division consists of the following Groups: \\ - Spectral Radiometry \\ - Spectrophotometry \\ - Radiometric Me asurement Services
}

\section{Radiation Source and Instrumentation Division}

\section{Develops, operates, and improves major NBS radiation facilities} including the electron Linac and race track microtron; develops, designs, and builds electronic and mechanical instrumentation for radiation programs and facilities; provides national leadership in the standardization of nuclear instrumentation; and develops new competence in radiation sources and instrumentation. The Division consists of the following Groups:
- Far UV Physics

- Electron Physics

- Photon Physics

\section{lonizing Radiation Division}

Provides primary national standards, measurement services, and basic data for applications of ionizing radiation; develops new methods of chemical and physical dosimetry; conducts theoretical and experimental research on the fundamental physical and chemical interactions of ionizing radiation with matter; provides essential standards and measurement support services to the National Measurement Support System for lonizing Radiation; and develops and operates radiation sources needed to provide primary radiation standards, fields, and well-characterized beams of radiation for research on radiation interactions and for development of measurement methods. The Division consists of the following office and Groups: 


\section{NBS MEASUREMENT SERVICES: CALIBRATION OF BETA-PARTICLE- EMITTING OPHTHALMIC APPLICATORS}

John S. Pruitt

Center for Radiation Research National Measurement Laboratory

National Bureau of Standards

Gaithersburg, MD 20899

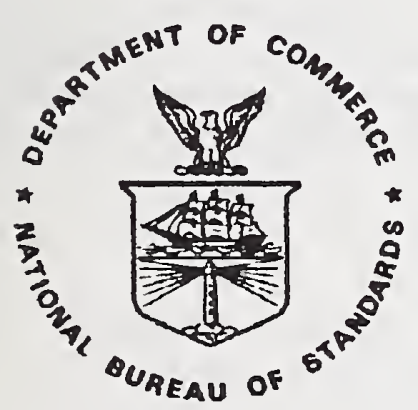

U.S. DEPARTMENT OF COMMERCE, Malcolm Baldrige, Secretary NATIONAL BUREAU OF STANDARDS, Ernest Ambler, Director

Issued July 1987 


\section{Library of Congress Catalog Card Number: 87-619844}

National Bureau of Standards Special Publication 250-9

Natl. Bur. Stand. (U.S.), Spec. Publ. 250-9, 36 pages (July 1987)

CODEN: XNBSAV

Commercial products-materials and instruments-are identified in this document for the sole purpose of adequately describing experimental or test procedures. In no event does such identification imply recommendation or endorsement by the National Bureau of Standards of a particular product; nor does it imply that a named material or instrument is necessarily the best available for the purpose it serves.

\section{U.S. GOVERNMENT PRINTING OFFICE} WASHINGTON: 1987

For sale by the Superintendent of Documents, U.S. Government Printing Office, Washington, DC 20402-9325 
The calibration and related measurement services of the National Bureau of Standards are intended to assist the makers and users of precision measuring instruments in achieving the highest possible levels of accuracy, quality, and productivity. NBS offers over 300 different calibration, special test, and measurement assurance services. These services allow customers to directly link their measurement systems to measurement systems and standards maint ained by NBS. These services are offered to the public and private organizations alike. They are described in NBS Special Publication (SP) 250, NBS Calibration Services Users Guide.

The Users Guide is being supplemented by a number of special publications (designated as the "SP 250 Series") that provide a detailed description of the important features of specific NBS calibration services. These documents provide a description of the: (1) specifications for the service; (2) design philosophy and theory; (3) NBS measurement system; (4) NBS operational procedures; (5) assessment of measurement uncertainty including random and systematic errors and an error budget; and (6) internal quality control procedures used by NBS. These documents will present more detail than can be given in an NBS calibration report, or than is generally allowed in articles in scientific journals. In the past NBS has published such information in a variety of ways. This series will help make this type of information more readily available to the user.

This document (SP 250-9), NBS Measurement Services: Calibration of Beta-Particle-Emitting Ophthalmic Applicators, by J. S. Pruitt, is the ninth to be published in this new series of special publications. It describes the calibration of ophthalmic applicators used in medical dosimetry for treatment of conditions that can be corrected with the shallow-dose exposures available from beta-particle radioactive sources. The calibrated quantity is the surface absorbed-dose rate to water averaged over the active area of the source (see test number $47030 C$ in the SP 250 Users Guide). Inquiries concerning the technical content of this document or the specifications for these services should be directed to the author or one of the technical contacts cited in SP 250.

The Center for Radiation Research (CRR) is in the process of publishing 21 documents in this SP 250 series, covering all of the calibration services offered by CRR. A complete listing of these documents can be found inside the back cover.

NBS would welcome suggestions on how publications such as these might be made more useful. Suggestions are also welcome concerning the need for new calibration services, special tests, and measurement assurance programs.

George A. Uriano

Director

Measurement Services
Chris F. Kuyatt

Director

Center for Radiation Research 


\section{ABSTRACT}

This service provides calibrations for ${ }^{90} \mathrm{Sr}+90 \mathrm{y}$ beta particle ophthalmic applicators. The calibration determines the average surface absorbed-dose rate to water over the active area of the applicator. The technique used is to measure current per unit mass of air at the active surface with an extrapolation ionization chamber, and to convert this into absorbed-dose rate with Bragg-Gray cavity ionization theory. The extrapolation chamber measurements are made in three parts. In the first part, a $1 \mathrm{~mm}$ diameter probe electrode is used to map the relative dose rate across the source surface, and to determine the active area. In the second part, the probe electrode is replaced by a $30 \mathrm{~mm}$ diameter electrode, and the test applicator is replaced by an NBS-owned applicator for quality assurance measurements. In the third part, the $30 \mathrm{~mm}$ electrode is used with the test applicator to determine the extrapolation curve slope at the source surface. The ratio of this slope to the source area, divided by the air density, yields current per unit air mass. The transformation to absorbed-dose rate is described. The component uncertainties are listed and are shown to yield a total uncertainty of $\pm 15 \%$, with the approximate significance of a $95 \%$ confidence limit. Data book measurements and a calibration report are given for one particular applicator.

Key words: absorbed dose rate; calibration service; extrapolation chamber; ophthalmic applicator; quality assurance measurements; surface dose rate. 
CONTENTS

Page

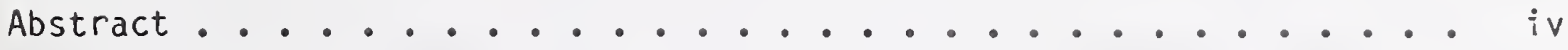
List of figures ...................... . . vi 1. The Calibration Service ................... 1 2. The General Approach . . . . . . . . . . . . . . 2 3. Description of the System ............... 3 4. Operational Procedures . . . . . . . . . . . . . 10 4.1 Current measurement and correction . . . . . . . . 10 4.2 Measurement of source area A . . . . . . . . . . . 12 4.3 Quality assurance measurements . . . . . . . . . . . 16 4.4 Current per unit air gap . . . . . . . . . . . 18

5. Surface Absorbed-Dose Rates . . . . . . . . . . 19

6. Cal ibration Uncertainty . . . . . . . . . . . 20 References . . . . . . . . . . . . . . 21

Appendix A. Examples from a datebook . . . . . . . . . . A-1 Appendix B. Sample calibration report . . . . . . . . . . . B-1

v 


\section{LIST OF FIGURES}

Page

Fig. 1. NBS-owned ophthalmic applicator SN $0258 \ldots \ldots$. . . . . 1

Fig. 2. Electron energy spectrum from a ${ }^{90} \mathrm{Sr}+90 \mathrm{Y}$ source . . . . 2

Fig. 3. Cross section of 30-mm diameter collecting electrode unit, showing relative position of high voltage electrode and

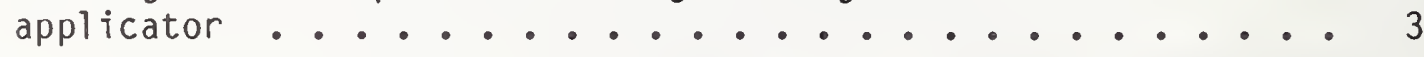

Fig. 4. Front view of extrapolation chamber and source support structure 5

Fig. 5. Side view of extrapolation chamber and source support structure 6

Fig. 6. Cross section of $1-\mathrm{mm}$ diameter collecting electrode unit . . 7

Fig. 7. Front view of extrapolation chamber housing and measuring

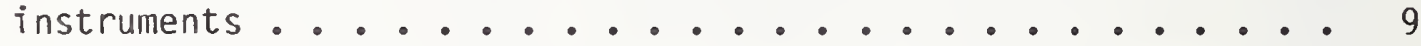

Fig. 8. Variation of ion current and parasitic current across

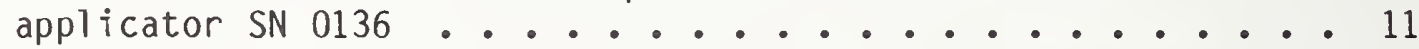

Fig. 9. Currents measured with the probe electrode across the face of SN D-402, plotted as a function of radius, measured from the center of the current distribution .......... 14

Fig. 10. Theoretical probe profiles for five different source distances, $\eta=\Delta z / R \ldots \ldots \ldots 15$

Fig. 11. Measured probe profiles of applicators SN 0258 and SN 157, in comparison with theoretical predictions for uniformly distributed sources .................... 16

Fig. 12. Front view of extrapolation chamber showing source support structure retracted for quality assurance measurements . . . 17 
This service is intended to provide calibrations for $90 \mathrm{Sr}+90 \mathrm{y}$ betaparticle applicators used in medicine for treatment of ophthalmic conditions. It was started in 1977. A typical ophthalmic applicator is shown in figure 1. It is a New England Nuclear Model NB-1. The National Bureau of Standards (NBS) owns an NB-1, serial number 0258. The quantity chosen for calibration is the average surface absorbed-dose rate to water over the active area of the source. If an applicator is immersed in water, or placed on a water-like material, such as tissue, the surface absorbed dose rate to water is the rate at which energy is absorbed by water from the beta particles, per unit mass of water, at the surface of the applicator. The applicators accepted for calibration generally have activities between $370 \mathrm{MBq}(10 \mathrm{mCi})$ and $7.4 \mathrm{GBq}$ $(200 \mathrm{mCi})$. (The corresponding range of surface absorbed-dose rates is from about $0.1 \mathrm{~Gy} / \mathrm{s}$ to about $2 \mathrm{~Gy} / \mathrm{s}$. ) Activities 1 ess than $370 \mathrm{MBq}$ are not very useful because of the long times required to obtain biologically significant exposures, while activities larger than $7.4 \mathrm{GBq}$ would produce radiation protection problems for the persons using and calibrating the applicator. The stated uncertainty is $\pm 15 \%$, with the approximate significance of a $95 \%$ confidence limit.

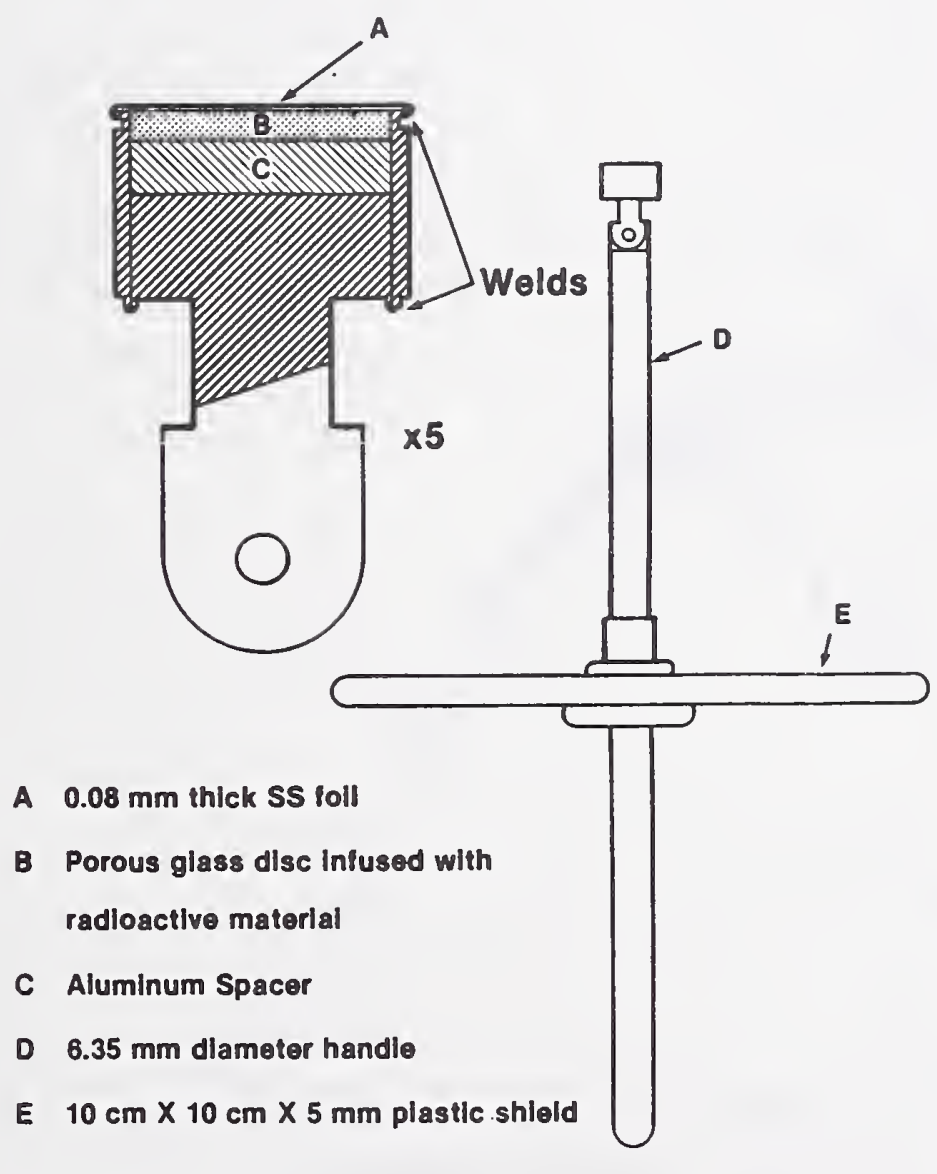

Fig. 1. NBS-owned ophthalmic applicator SN 0258. 
This service was called $8.4 \mathrm{~K}$ in the old SP250 manual. The designation has been changed to $47030 \mathrm{C}$ in the 1986 version of SP250.l The latter also contains instructions for shipping and handiing the applicators.

A report entitled "Calibration of Beta-Particle Ophthalmic Applicators at the National Bureau of Standards" has been published in the Journal of Research of the NBS. 2 It contains much of the information given in this report. Examples from a data book are given in Appendix $A$, and a sample calibration report is given in Appendix $B$.

\section{The General Approach}

The average surface absorbed-dose rate to water is determined from ionization-chamber measurements in air, and converted to water with Bragg-Gray cavity-ionization theory, a routine conversion described in detail in section 5. Water was the medium chosen for calibration because it is universally available and its properties are close to those of tissue. The primary alternative method of calibration uses thermoluminescent dosimeters, but this method was rejected because these dosimeters must be calibrated with a different radiation source. Use of the Bragg-Gray theory requires knowledge of only a well-known constant, the energy required to produce unit ionization in air, and the ratio of averaye stopping powers for water and air. This ratio can be calculated from tabulated stopping powers if the beta-particle energy spectrum is known. Figure 2 shows a typical strontium 90-yttrium 90 energy spectrum. It was obtained with a 5-mm-deep silicon surface-barrier detector at room temperature in air, under $0.013 \mathrm{~mm}$ of aluminized polyethylene terephthalate. The measurements were made at a distance of $11 \mathrm{~cm}$ from a Buchler-Amersham source, and have not been corrected for either backscatter or self-absorption. The spectral shape need not be known with great precision, however, since stopping-power ratios vary slowly with beta-particle energy.

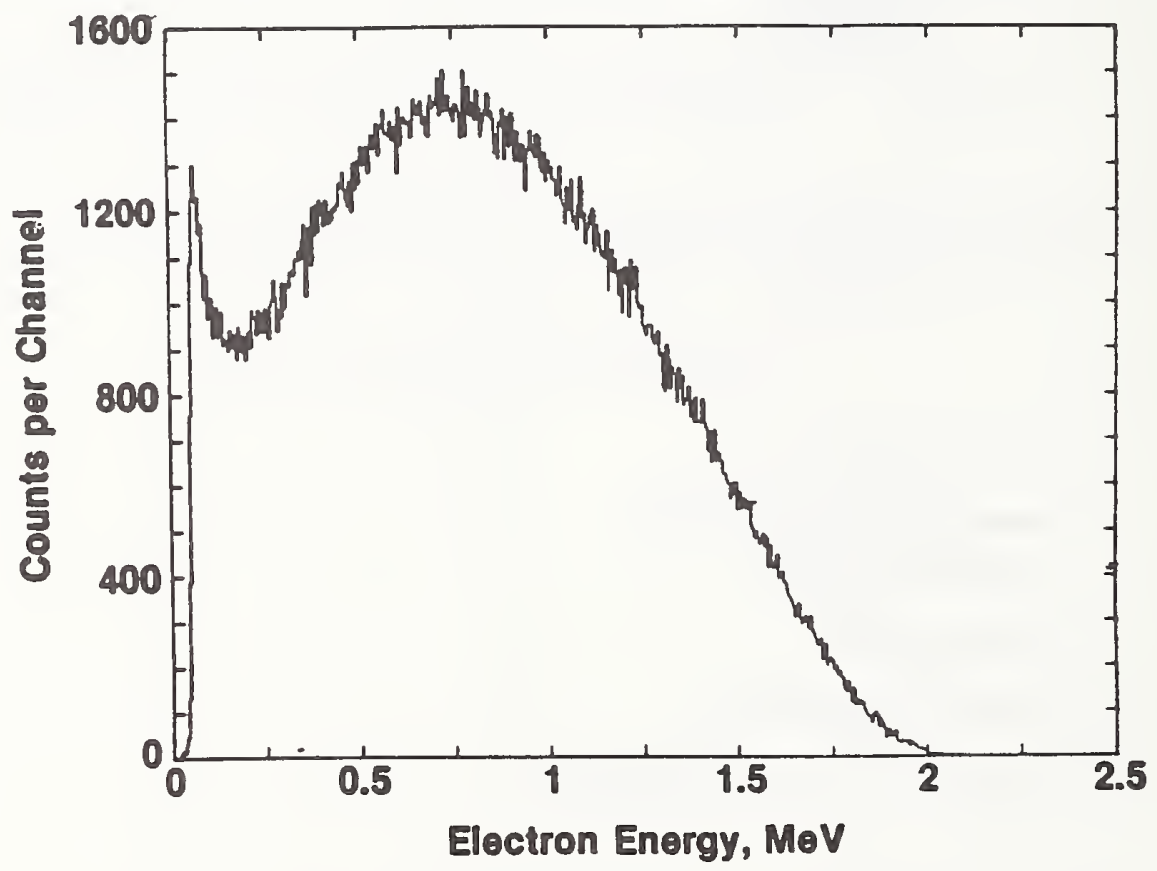

Fig. 2. Electron energy spectrum from a ${ }^{90} \mathrm{Sr}+90 \mathrm{y}$ source. 
The determination of average surface absorbed-dose rate is performed in two steps using ionization chambers of different diameters, because two quantities need to be measured. The total current per unit air yap at the source surface, $(I / d)_{0}$, is measured with an ion chamber at least two $B$-particle ranges larger in diameter than the active area of the source; the active area $A$ of the source is determined by mapping with an ion chamber much smaller in diameter than the diameter of the active area. In practice, the two measurements are made with the same ionization chamber, but the size of the collecting electrode is changed. The average surface absorbed-dose rate is directly proportional to the ratio $(I / d) /(\rho A)$, where $\rho$ is air density. This ratio has dimensions of current per unit mass of air $(A / \mathrm{kg})$.

The general plan of the calibration is to measure ionization current per unit mass of air with the applicator at several distances from the center of the ionization chamber air gap, and to extrapolate to zero distance and zero air gap to obtain a value at the surface of the applicator. Sections 3 and 4 are concerned with this determination of extrapolated current per unit mass of air. Section 5 describes the calculation of the absorbed-dose rate, and section 6 is a discussion of the uncertainties inherent in this calibration method.

3. Description of the System

The extrapolation ionization chamber is essentially the same as that described by Loevinger and Trott, 3 with several collecting electrodes which can be interchanged and a thin aluminized-plastic-film highvoltage electrode. The relative position of the electrodes and an ophthalmic applicator under study are shown in figure 3 . The extrapolation chamber itself is a parallel plate capacitor of variable plate separation, d. The guard electrode is yrounded and the collecting electrode potential is very close to ground. In this condition, the lines of force are perpendicular to the collecting electrode, and the collecting electrode receives only charged particles that have been generated in the cylindrical air volume defined by $d$ and the collecting electrode area, $A_{C}$. The extrapolation chamber has means for both changing $d$ and for measuring this change, but does not provide an absolute measure of $d$ itself without extrapolation.

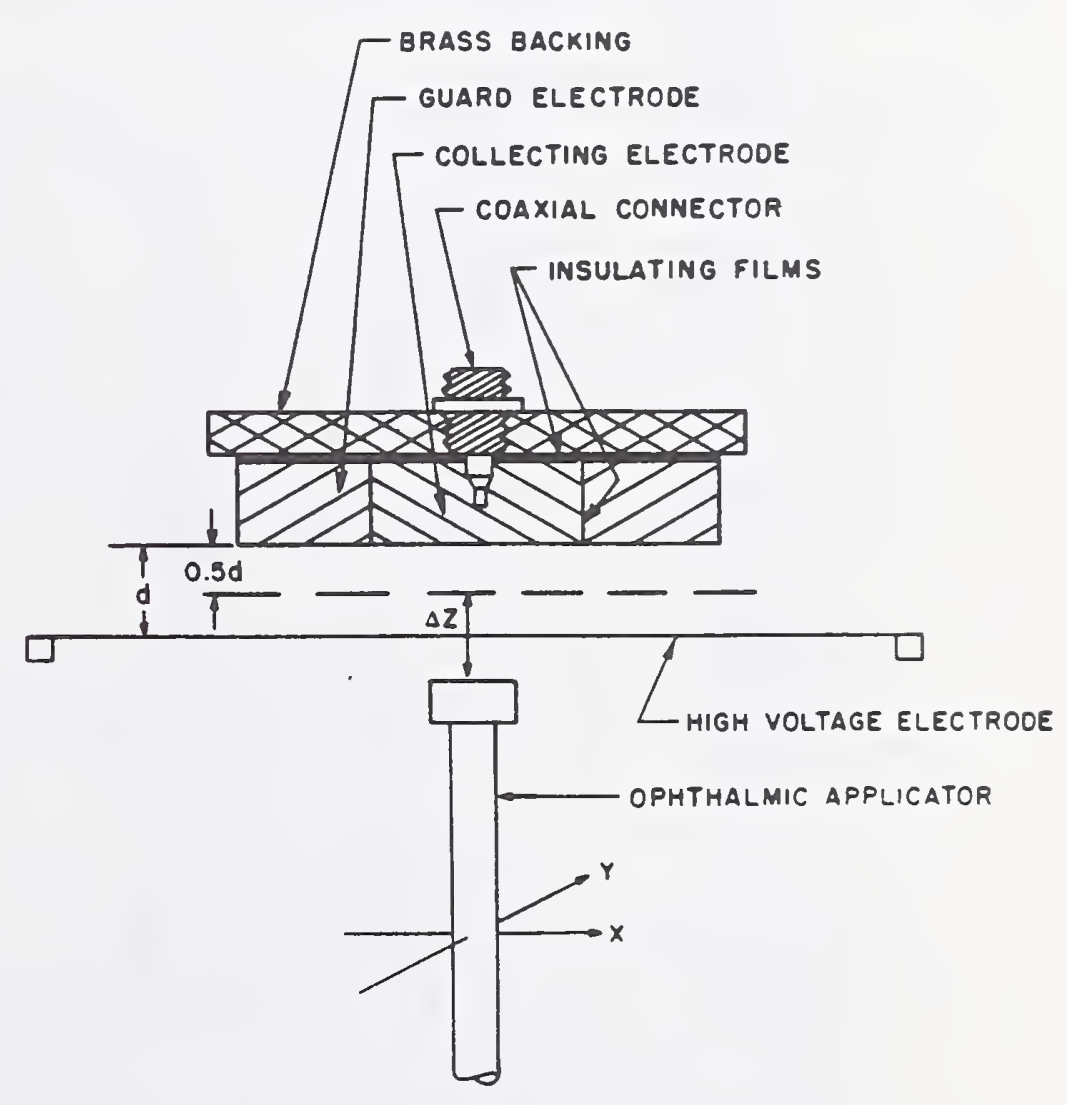

Fig. 3: Cross section of 30-mm diameter collecting electrode unit, showing relaitive position of high voltage electrode and applicator. 
The particular collecting electrode shown has a diameter of about $30 \mathrm{~mm}$ and is surrounded by a guard electrode with an outside diameter of $50 \mathrm{~mm}$. Both guard and collecting electrodes are made of 8-mm thick A-150 conducting plastic, electrically isolated with 30-um plastic film held in place with epoxy cement. The high-voltage electrode is Mylar aluminized on the inside surface, with a diameter of $70 \mathrm{~mm}$ and a thickness of $0.7 \mathrm{mg} / \mathrm{cm}^{2}$ (about $5 \mu \mathrm{m}$ ).

Figures 4 and 5 are respectively a $3 / 4$ front view and a side view of the apparatus, showing the extrapolation chamber above and the NBS ophthalmic applicator SN0258 below. (The applicators in figures 4 and 5 have been retracted from their normal position by about $3 \mathrm{~cm}$ for clarity.) The extrapolation chamber housing is mounted on the underside of the 6-mm thick triangular brass top plate, which is supported on three 19-mm diameter brass posts. The lower half of this housing, including the bronze ring on which the circumferential scale is engraved, the captain's wheel, and the mylar HV electrode foil, can be rotated to change d, the chamber plate separation. Each complete revolution of the captain's wheel changes d by $0.635 \mathrm{~mm}$ (40 turns/inch). The internal collecting-electrode-guard-electrode unit of figure 3 cannot be seen in figure 4 , but it rests on three brass supports rigidly attached to the top plate in figure 4.

The orientation of the captain's wheel, uniquely related to the plate separation $d$, can be specified by a single number, the angle of rotation (which may increase to many multiples of $2 \pi$ radians). In practice, that angle is broken down into two related components, $\theta$ and $g$. The number $\theta$ is onehundredth of the number read from the circumferential scale shown in figure 4. This scale consists of 100 divisions, so $\theta$ varies from 0 to 1 in one revolution. The number $g$ is read from the dial gauge visible at the top of figure 4. There are two scales on the dial gauge. The larye scale is divided into 100 divisions, with 0.001 inches per division. The small scale is divided into 10 units, with 0.1 inches between units. The dial gauge reading $\mathrm{g}$ is the sum of the small gauge reading, a whole number, and the large gauge reading, a fraction between zero and unity. Its units are tenths of an inch.

The two numbers $g$ and $\theta$ can be related by setting $\theta$ to zero and then rotating the dial gauge until the large needle points to a multiple of 0.25 (four revolutions of the captain's wheel are equivalent to one revolution of the large dial gauge needle). Then the electrode separation, in $\mathrm{mm}$, can be written:

$$
d=2.54\left(g_{0}-g\right) \quad \text { where } g=g_{1}-\frac{\theta}{4}
$$

and $g_{0}$ is the dial gauge needle reading when $d=0 . g_{1}$ is the closest multiple of 0.25 larger than $g$ (for two examples, if $\mathrm{g}=5.173$ (or 4.635 ), $g_{1}=5.25$ (or 4.75), and $\theta=0.308$ (or 0.460$)$ ). $g_{0}$ must be measured by extrapolation, as described in the next section.

The collecting electrode shown in figure 3 has a much larger area than the active area of all ordinary ophthalmic applicators, which have diameters between $6 \mathrm{~mm}$ and $9 \mathrm{~mm}$. This type of collecting electrode is used to determine the ratio $(I / d)_{0}$, where $I$ is the ionization current yenerated in the air volume defined by the collecting area $A_{C}$ and the electrode separation $d$. The ratio $I / d$ is a function of both $d$ and the applicator distance $\Delta z$, and the zero subscript refers to the 1 imiting case where both $d$ and $\Delta z$ are zero. This limiting value of $I / d$ is a characteristic of the source and of the electrode material and is independent of $A_{C}$, if $A_{C}$ is sufficiently large. 


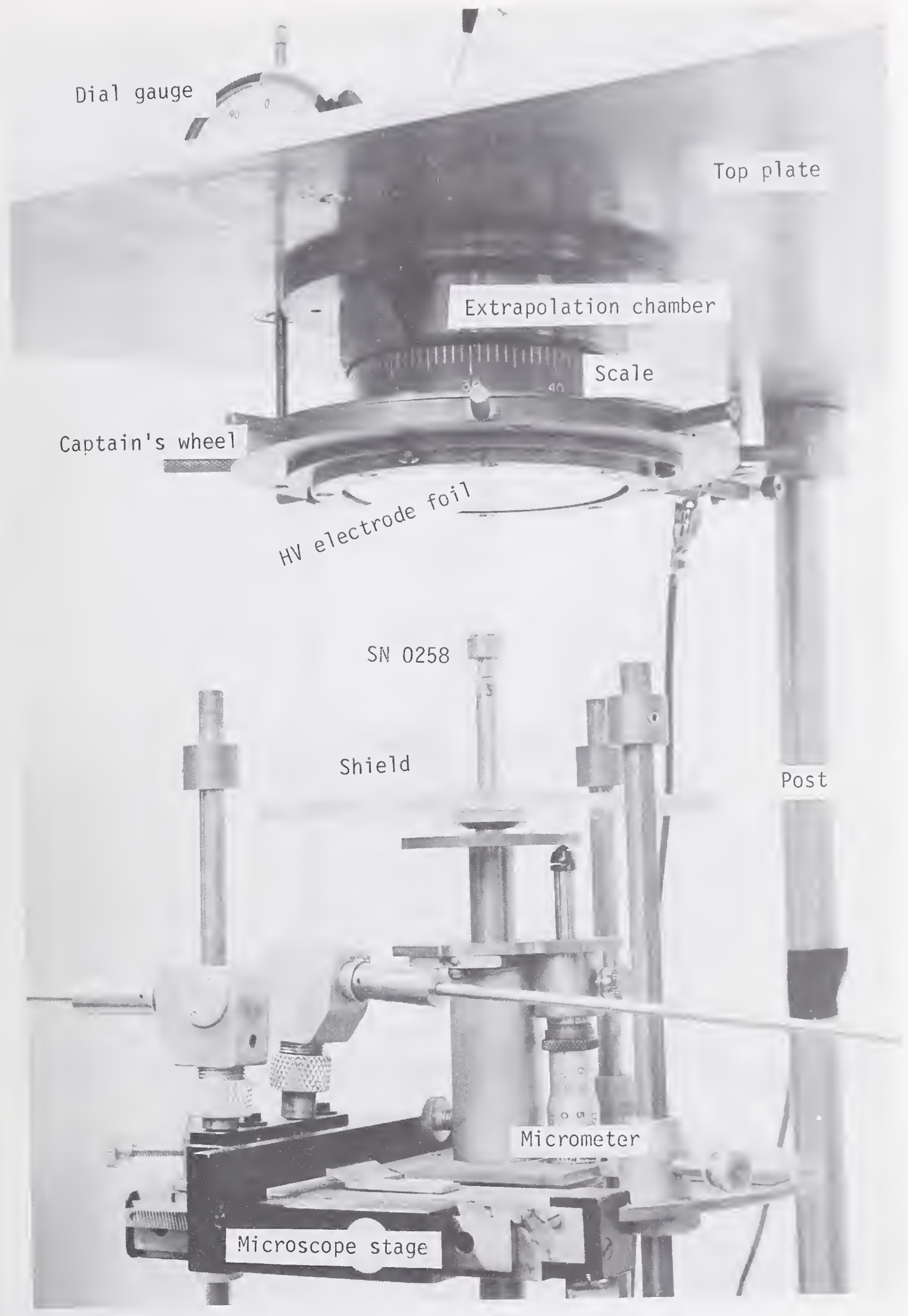

Fig. 4: Front view of extrapolation chamber (above) and source support structure. NBS applicator SN 0258 is shown. 


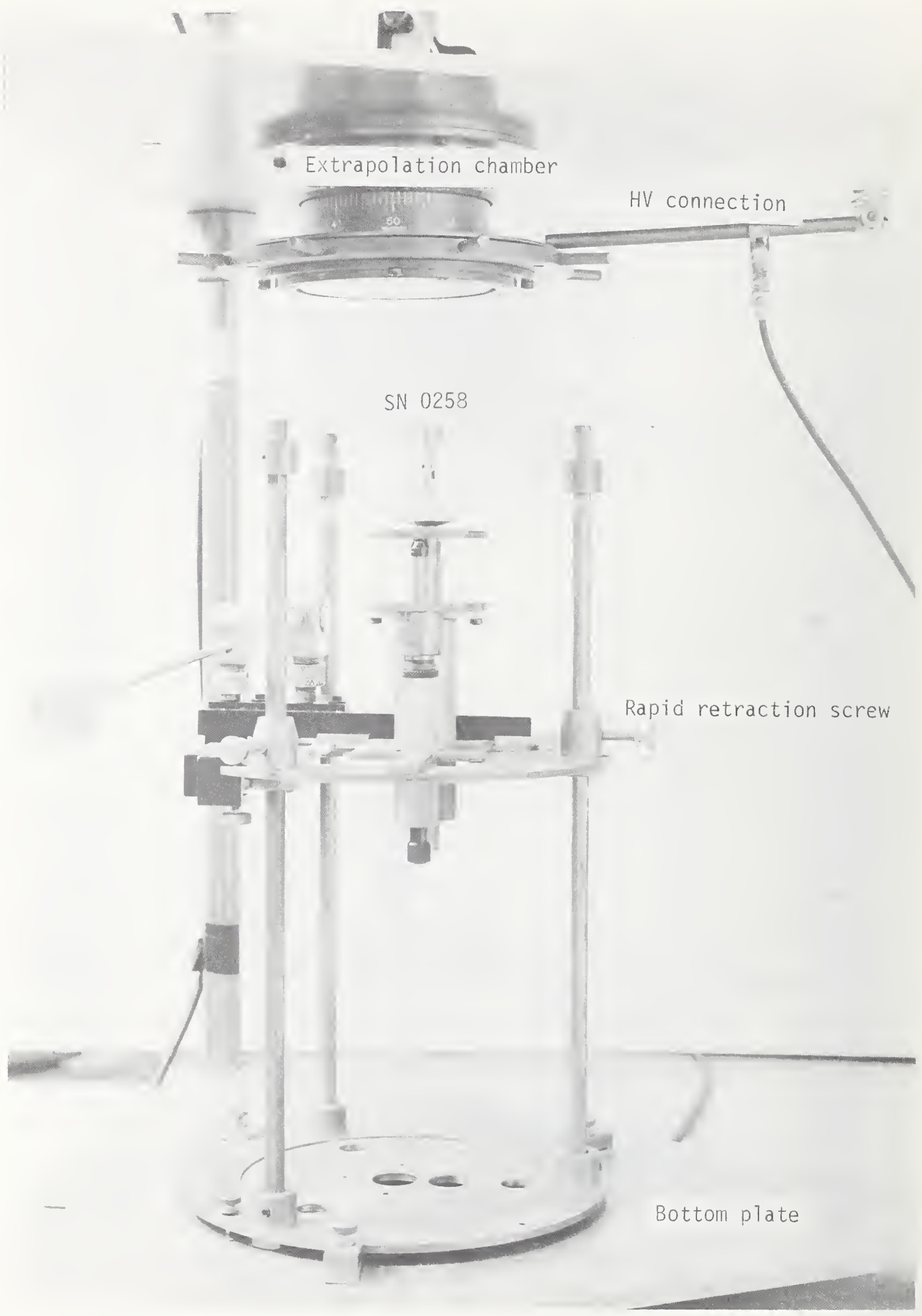

Fig. 5: Side view of extrapolation chamber (above) and source support structure. NBS applicator SN 0258 is shown. 
For measurements of the source area $A$, the collecting-electrodeguard-electrode unit of figure 3 can be lifted out of the extrapolation chamber and replaced by a unit with approximately the same outline but with a much smaller collecting electrode, shown in cross section in the upper diagram in figure 6 . This probe electrode is a $0.6-\mathrm{mm}$-diameter pencil lead, shown as a solid black vertical strip in both upper and lower parts of figure 6 . It is surrounded by a $0.4-\mathrm{mm}$-thick insulating ring of epoxy resin, giving an effective probe diameter of about $1 \mathrm{~mm}$. The probe is surrounded by a graphite guard ring, $19 \mathrm{~mm}$ in diameter. This in turn is surrounded by a 50-mm-diameter acrylic ring that is recessed from the surface of the graphite by about $0.4 \mathrm{~mm}$. The graphite guard ring is grounded through a graphite coating on the acrylic ring.

The probe electrode is more complex than the $30-\mathrm{mm}$ electrode because of the special precautions taken to make the $0.4-\mathrm{mm}$ epoxy ring of uniform thickness. The lower diagram in figure 6 shows how this was achieved with al ignment holes which were eventually removed. The alignment holes are in graphite, outside the two Finish Planes, completely filled by the pencil lead. After the epoxy has dried, the unit is machined until it looks like the graphite-epoxy insert in

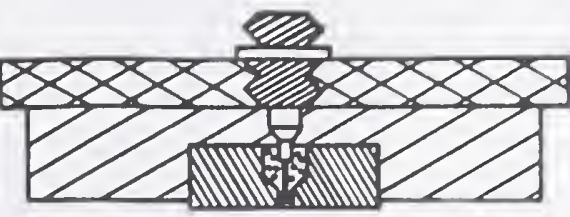

\section{Graphlte}

Epoxy

Acryllo

\section{Brase}

\section{Connector}

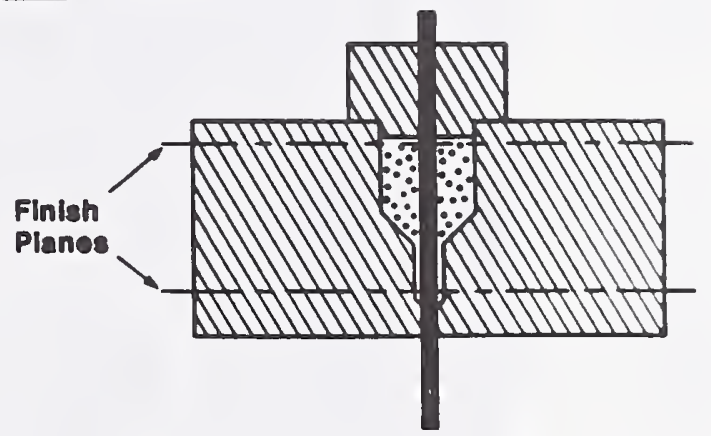

Fig. 6: Cross section of 1-mm diameter collecting electrode unit (top) and the technique used to center pencil-lead collecting electrode (bottom). After machining, only the material between the two finish planes remains.

the upper diagram. It was necessary to use a slow-drying epoxy for the insulator, from which the bubbles had been removed by spinning in a centrifuge.

The ophthalmic applicator can be moved in three perpendicular directions. The $x$ and $y$ motions (along axes shown in fig. 3) are provided by the microscope stage, and are concrolled by two horizontal rods with knurled knobs at the ends. These rods are a safety measure, allowing the $x$ and $y$ positions to be set to within $\pm 0.05 \mathrm{~mm}$ without excessive radiation exposure to the fingers. Motion along the $z$ axis (perpendicular to the $x-y$ plane) is controlled by the vertical barrel micrometer shown just to the right of the applicator in figure 4. While changing $\Delta z$, the operator's fingers are protected both by the brass plate on which the microscope stage is mounted and by the 1/4-inch-thick plastic shield attached to the applicator handle. 
During measurements of both $(I / d)$ and $A$, the source surface must be raised until it touches the extrapolation chamber high-voltage-electrode foil. (This does not produce a short circuit since only the inner foil surface is at high voltage.) For determination of the zero-separation dial-gauge reading $g_{0}$, or for source insertion and removal, the source support structure has to be retracted by about $20 \mathrm{~cm}$. These large changes in the $z$ coordinate are produced by releasing the three rapid retraction screws shown in figure 5 and sliding the microscope-stage down on the three vertical steel rods shown. The barrel micrometer is used only for fine control of $\Delta z$.

Figure 7 shows both the apparatus and the measuring instruments. The apparatus, at the right in figure 7 , is surrounded on three sides by a $3 / 8-$ inch-thick transparent plastic housing, intended for radiation protection of the operator who sits facing the front panel. His hands can be inserted into the housing for source and/or chamber manipulation through doors on either side. The operator's torso and face are always protected by $3 / 8$-inch of plastic. The applicator shown inside the housing in figure 7 has been covered with a lead cap, to protect the operators fingers during source/chamber manipulation. This lead cap was put in position with the tongs shown lying on the bottom plate of the apparatus in figure 7 .

The extrapolation-chamber collecting electrode is connected via low-noise coaxial cable to the input of a Keithley $610 \mathrm{C}$ electrometer. This instrument has a dial readout that is usually turned off. In its place, a Digitec 266 DC voltmeter (DVM) provides a digital readout of the electrometer feedback voltage. The $X 1$ Output of the $610 \mathrm{C}$ is connected to the Hi terminal of the DVM, and the Guard terminal of the $610 \mathrm{C}$ is connected to the Lo terminal of the DVM. The $610 \mathrm{C}$ is used with the Feedback switch set to Fast, and the mode switch set to $10^{-8}, 10^{-9}$, or $10^{-10}$ coulombs full scale.

Underneath the electrometer in figure 7 is a locally made DVM timer, which controls the Digitec DVM display. The timer output is connected to terminals D6 on the DVM card-edge connector, so that the DVM displays the instantaneous electrometer feedback voltage only when it gets a positive pulse from the timer. The front panel of the timer contains an ERC counter, an ITC comparator, and a Start button. When the Start button is pushed, the timer generates a pulse, the DVM displays an initial voltage, and the counter starts counting elapsed time. When the counter reaches the pre-set comparator number, it generates a second pulse, the DVM displays a final voltage, and the counter stops counting. For the particular timer shown in figure 7 , the time unit for both counter and comparator is centiseconds. (For some of the local DVM timers, the time unit is milliseconds.)

Underneath the Digitec DVM is a high-voltage power supply, connected between the chamber high-voltage electrode and ground. This is a Keithley Model 240A, which can provide from 0 to 1200 volts potential of either polarity. (Although this power supply could be replaced by one delivering 0 to $100 \mathrm{~V}$, both the amplitude and the stability of the $240 \mathrm{~A}$ have proven adequate.) The voltage is connected to the chamber nigh voltage electrode by means of the brass rod shown at the upper right in figure 5, which makes a sliding contact with a brass ring mounted on insulators above the captain's wheel. The voltage selected in any given situation depends on the electrode separation d. During extrapolation measurements, a constant potential gradient is maintained, since this both minimizes the corrections and exerts a 


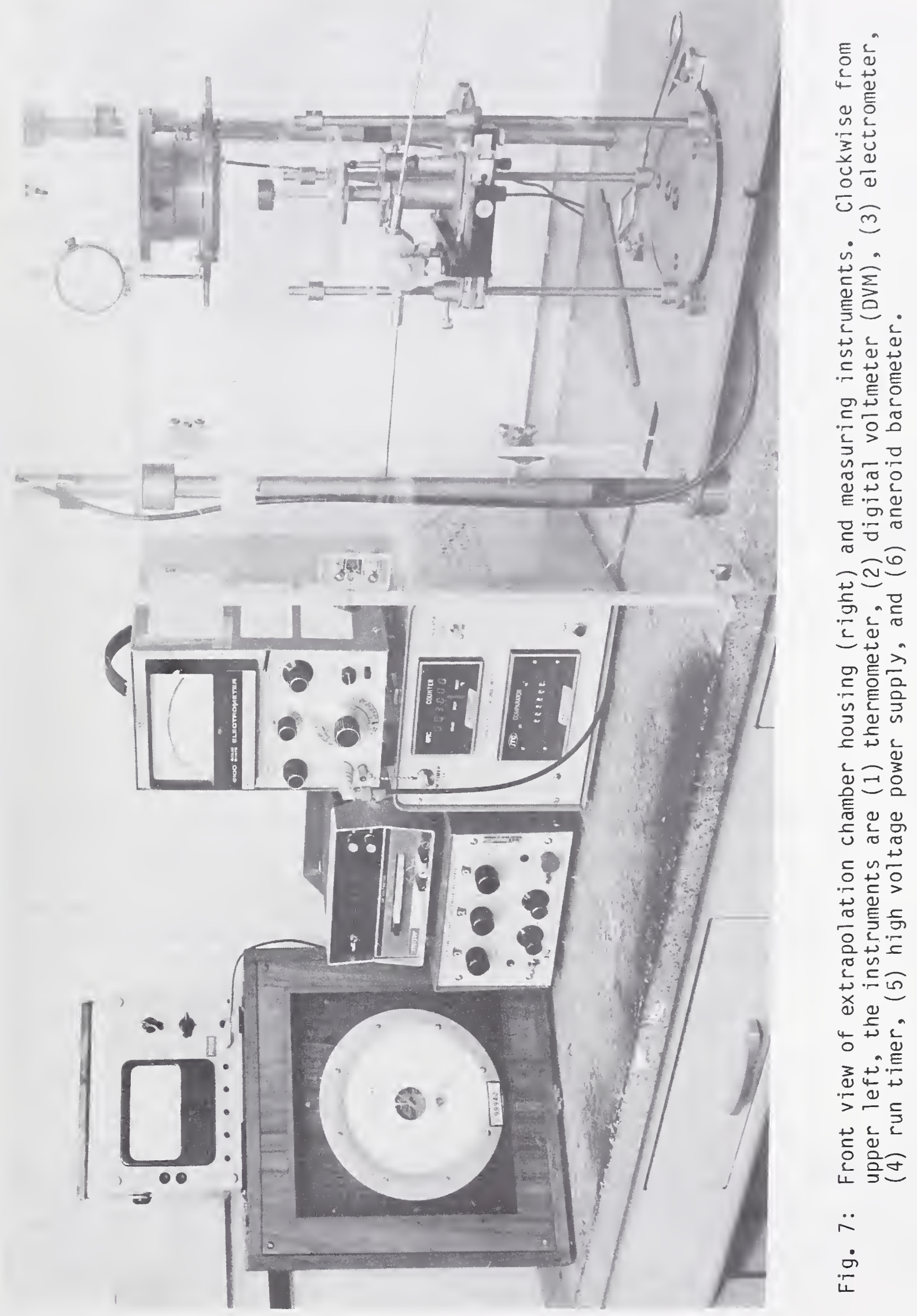


constant force on the flexible high voltage electrode. It has been found that electrode flexure is negligible if the voltage gradient does not exceed $40 \mathrm{~V} / \mathrm{mm}$. Measurements have been made successfully with gradients between $10 \mathrm{~V} / \mathrm{mm}$ and $40 \mathrm{~V} / \mathrm{mm}$. Corrections have to be applied in all cases, as explained in a later section.

The two instruments at the extreme left-hand side of figure 7 are for determining the relative air density inside the chamber. The lower instrument is a Wallace and Tiernan Model FAl39 aneroid barometer, which reads ambient air pressure in units of millimeters of mercury ( $\mathrm{mmHg}$ ). The upper instrument is a Yellow Springs Instrument Co. Tele-Thermometer, to which is attached a long cable with a temperature probe at the end. This probe usually sits in the chamber well, immediately above the brass backing of the collectingelectrode-guard-electrode unit, and gives an approximate measure of the chamber air temperature.

\section{Operational Procedures}

This section contains descriptions of the measurement procedures for both current per unit air gap, (I/d) , and source area, A, as well as correction formulas and quality assurance measurements. An example of data collection and analysis is given in Appendix A, taken directly from databook 863. Appendix $B$ shows the report issued for this particular ophthalmic applicator.

\subsection{Current measurement and correction}

The extrapolation chamber current measured in amperes during a run is:

$$
I=C \times \frac{V_{F}-V_{I}}{\Delta t}
$$

where: $C$ is the electrometer capacitance, in farads,

$V_{I}$ and $V_{F}$ are initial and final DVM voltage measurements, in volts, $\Delta t$ is the run time, in seconds, determined by the DVM timer.

The value of the capacitance $C$ must be determined for each electrometer scale by independent measurements. For the particular electrometer shown in figure 3, NBS \#184539, the capacitances measured in March 1982 were:

\begin{tabular}{cc} 
Ful1-scale $(C)$ & Capacitance $(\mathrm{pF})$ \\
\hline $10^{-8}$ & 10,000 \\
$10^{-9}$ & $1,011.9$ \\
$10^{-10}$ & 103.94
\end{tabular}

(These numbers have changed by several tenths of $1 \%$ from earlier measurements in 1979.) Each voltage determination is the product of a DVM reading and a DVM correction factor. For the DVM of figure 7, NBS \#183047, the correction factor measured on 86 Feb 21 for the $2-V$ (or 20-V) scale is $0.9977(0.9991)$. (These have changed by $0.1 \%(0.1 \%)$ over the course of 3 years). 
The measured current is the sum of two components, an ion current generated in the chamber air gap by interaction between air molecules and the incident beta-particles, and a parasitic current generated in the body of the collecting electrode by beta-particles coming to rest. These two components can be separated by making measurements with both positive and negative high-voltage polarity. The ion current component will change sign when the polarity changes, while the parasitic component will not.

If $\mathrm{I}^{+}$and $\mathrm{I}^{-}$are currents measured with positive and negative polarity respectively, the ion current is:

$$
I=\frac{I^{+}-I^{-}}{2}
$$

where $\mathrm{I}^{-}$is normally a negative number. The parasitic current is $\left(\mathrm{I}^{+}+\mathrm{I}^{-}\right) / 2$ and may be either positive or negative. It has no immediate application, but is usually recorded because abrupt changes may indicate measurement problems. The data tabulated in Appendix $A$ are good examples of the normal range of variation of the parasitic current, labeled $\bar{I}_{B}$. Page $136^{\prime}$ lists data taken with a 30-mm diameter collecting electrode such as shown in figure 3 . The $\bar{I}_{B}$ measurements in this case show a normal progression from about -40 pA to about $-38 \mathrm{pA}$ as the chamber air gap increases from $0.5 \mathrm{~mm}$ to $2.5 \mathrm{~mm}$. Departures from this progression by $20 \%$ or more usually indicate that one of the system electronic components is malfunctioning.

Figure 8 shows the variation of both the ion and parasitic currents across the face of the most asymmetric applicator that has been studied in this laboratory. The measurements were made with the probe electrode, using an electrode spacing, $d$, of $0.05 \mathrm{~mm}$ and an applicator distance, $\Delta z$, of $0.4 \mathrm{~mm}$. The asymmetry of the ion current is presumably caused by an uneven distribution of activity across the applicator face. The tails of the ion current distribution are caused by beta particles that leave the applicator with large velocity components perpendicular to the beam direction. The tails rapidly become more prominent as the applicator distance $\Delta z$ increases.

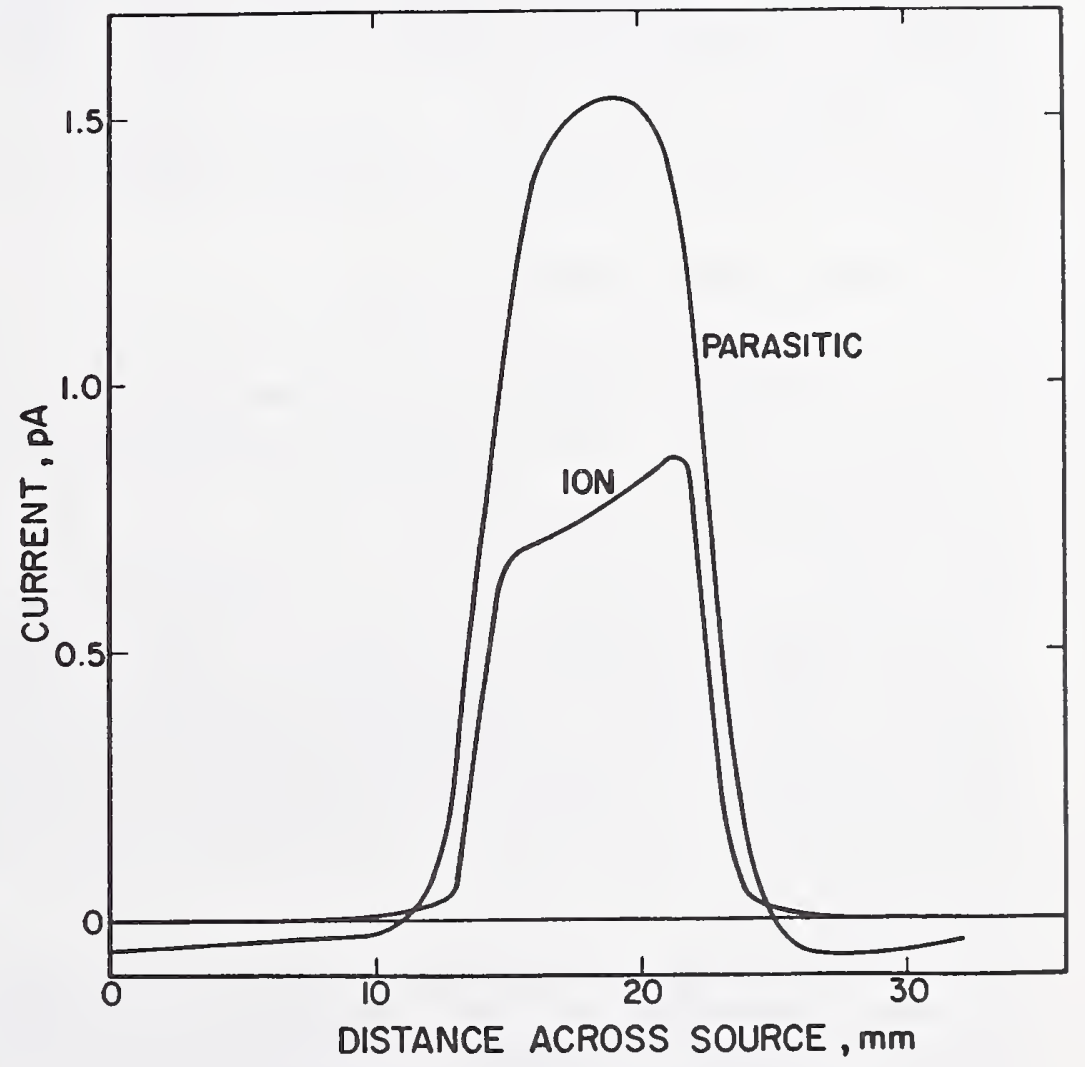

Fig. 8: Variation of ion current and parasitic current across applicator SN 0136. 
The graph of parasitic current in figure 8 shows evidence both of electrons coming to rest in the collecting electrode (the central peak of the distribution), and background (the negative tails). The central peak of the parasitic current is more symmetrical than the ion current peak, probably because of multiple scattering of the primary beam in the plastic backing of the electrode, which tends to round off the edges of the distribution. The parasitic background is a current of about 10-50 fA. The ion current background is negligible.

The ion current calculated with eq (3) must be multiplied by two correction factors, one to correct air density inside the chamber to $22^{\circ} \mathrm{C}$ and $760 \mathrm{mmHg}$, and the other to correct for ion recombination and diffusion inside the chamber. These factors are given by:

$$
f_{\text {temp }}=\frac{760(T+273.15)}{295.15 P}
$$

Where $\mathrm{T}$ is the temperature in degrees Celsius and $\mathrm{P}$ is the pressure in $\mathrm{mmHg}$;

$$
f_{\text {recom }}=\left\{\left(1-\frac{50.5 I d}{A X^{2}}\right)\left(1-\frac{0.0044}{X}\right)\left[1-\left(17.24 \times 10^{-5}\right)\left(\frac{T+273.15}{X d}\right)\right]\right\}^{-1}
$$

where $I$ is ion current in $\mathrm{nA}$, $d$ is electrode separation in $\mathrm{mm}$, $\mathrm{A}$ is source area in $\mathrm{mm}^{2}$, and $X$ is potential gradient, in $\mathrm{V} / \mathrm{mm}$. Equation (4) comes from the ideal gas $1 \mathrm{aw}$, and eq (5) comes from Bohm, 4 with bracketed terms for general recombination, initial recombination, and diffusion, reading from left to right. (For the data 1isted on p. 136 of Appendix A, as the chamber air gap increases from $0.5 \mathrm{~mm}$ to $2.5 \mathrm{~mm}$, the general recombination term decreases from 0.9996 to 0.9911 , the initial recombination term holds steady at 0.9998 , and the diffusion term increases from 0.9949 to 0.9990.)

\subsection{Measurement of source area $A$}

This operation is performed with the small collecting electrode, or probe (fig. 6), using a fixed small air gap d (fig. 3), and with $\Delta z$ just slightly larger than d/2. Current measurements can be made at different points in the $x-y$ plane over a large enough area so that the current drops to less than half its maximum value in all directions. If the $x-y$ plane, determined by the microscope stage, is parallel to the plane of the chamber high-voltage electrode, this mapping can be done with no change in $\Delta z$. These planes are seldom parallel, however, because the rapid retraction mechanism described in section 3 (for large changes in $\Delta z$ ) is only a crude adjustment. With the vertical position $\Delta z$ set so that the applicator is close to but not touching the HV electrode foil when the applicator is centered, the changes in $x$ and $y$ that occur during mapping of the source may cause the applicator to run into the electrode, diminishing the air gap in the chamber and reducing the chamber sensitivity.

The operator can avoid this effect by simply sighting by eye to determine when the applicator is close to the HV electrode foil, independent of the barrel inicrometer readings. A simple test can be run once, to get a feel for what the position of the two components looks like when they are too close. 
With the applicator and HV-electrode foil just barely separated by eye, the operator can measure the ion-chamber current, reduce the separation by $0.01 \mathrm{~mm}$ using the barrel micrometer reading, repeat the current measurement, etc. It will be found that the current increases slowly as $\Delta z$ is reduced, until the two components touch. With further reduction of $\Delta z$, the current drops rapidly.

For most ophthalmic applicators, the uppermost surface is not flat, as shown in figure 3 , but slightly convex. The orientation of the applicator should be such that the convex surface would be first to touch the HV electrode when $\Delta z$ is reduced to $d / 2$. In extreme cases, the head of the applicator is cocked relative to the handle, so that the rim of the surface meets the HV electrode first. In such cases, it may be possible to compensate for this awkward alignment by tilting the source-support plate, depressing one or more of the three fittings attaching it to the vertical steel rods.

In preparing for source-area measurements, it is necessary to find $\mathrm{g}_{0}$, the $d=0$ point on the dial-gauge scale. This can be done with the source in position, but retracted by about $20 \mathrm{~cm}$. In this condition, the corrected current is a linear function of $d$, and the $d=0$ point can be determined by measurements with several air gaps and linear extrapolation to zero current. The corrections required are the two listed in the preceding section, $f_{\text {temp }}$ and $f$ recom, plus a third factor that corrects for scatter from the sidewalls of the chamber, and a fourth factor that corrects for attenuation in the air between source and chamber. These extra factors are appreciable only when the source-chamber distance is large. At $20 \mathrm{~cm}$, the empirical formulas for these factors are:

$$
f_{\text {scat }}=1-0.0094 d
$$

where $d$ is the chamber air gap in $\mathrm{mm}$, and:

$$
\begin{aligned}
f_{\text {atten }} & =\left(1+0.077 h-0.335 h^{2}\right)^{-1} \\
h & =1-\left(f_{\text {temp }}\right)^{-1} .
\end{aligned}
$$

Equation (6) was derived by increasing the thickness of scattering material, and eq (7) comes from experiments at reduced atmospheric pressure. 5 (There is no need to determine $g_{0}$ each time the probe electrode is used. Its value may change slightly when this electrode is removed and replaced, but the source area measurement is insensitive to this change.)

The mapping itself consists of repeated measurements with different $x$ and y coordinates but with similar $\Delta z \cong d / 2$. The air gap d should be reduced to $0.1 \mathrm{~mm}$ or $0.2 \mathrm{~mm}$, with the chamber voltage gradient set for about $20 \mathrm{~V} / \mathrm{mm}$. For each change of $x$ and/or $y$, the applicator must first be retracted $(\Delta z>d / 2)$ and then returned to $\Delta z \cong d / 2$ after the change, because the $x-y$ plane and the HV foil plane are not parallel. The theoretical description of the chamber current given in eq (8), below, can be used to show that small variations in $\Delta z$ have a negligible effect on the measured currents. 
If $x_{0}$ and $y_{0}$ are the values of $x$ and $y$ with the applicator centered by eye relative to the collecting electrode, it has been found that 36 current measurements at $2-m m$ intervals over the ranges $x_{0}-5 \leqslant x \leqslant x_{0}+5 \mathrm{~mm}$ and $y_{0}-5 \leqslant y \leqslant y_{0}+5$ cover a large enough area so that the current drops to less than half its maximum value in all directions. (In the Appendix A example, the array of current measurements is plotted at the top of p. 135.) Along each $x=$ constant (or $y=$ constant) line there are two values of $y$ (or $x$ ) for which $I=I_{\max } / 2$. These two $y_{\frac{1}{2}}\left(\right.$ or $x_{\frac{1}{2}}$ ) values can be calculated by 1 inear interpolation, and their average is a measure of one coordinate of the center of the distribution, $y_{c}\left(\right.$ or $\left.x_{c}\right)$. This may or may not coincide with the originally estimated center coordinate $y_{0}\left(\right.$ or $\left.x_{0}\right)$. At the end of the mapping measurements, an average $\bar{y}_{c}$ and $\bar{x}_{c}$ can be calculated. (In the Appendix $A$ example, $y_{\frac{1}{2}}$ and $x_{\frac{1}{2}}$ are listed on p. 135 as $y^{ \pm}$and $x^{ \pm}$, while the values of $y_{C}$ and $x_{c}$ are ${ }^{\frac{1}{2}} l$ isted ${ }^{2}$ as $y_{a v}$ and $x_{\text {ave }}$. The averages $\bar{y}_{C}=35.45 \mathrm{~mm}$ and $\bar{x}_{c}=121.88 \mathrm{~mm}$, are not far from the original $y_{0}=36.0 \mathrm{~mm}$ and $x_{0}=121.2 \mathrm{~mm}$. ) I is plotted as a function of $r=\sqrt{\left(x-\bar{x}_{c}\right)^{2}+\left(y-\bar{y}_{c}\right)^{2}}$, as shown in figure 9 for a particular applicator. (In the Appendix A example, this plot is at the bottom of p. 135.)

For most applicators, the current decreases monotonically with increasing radius as in figure 9 . A $50 \%$ radius $\bar{R}$ can be read directly from the graph, and the area calculated from this as $\pi \bar{R}^{2}$. This is a close approximation to the real area $\pi R^{2}$ if the chamber spacing $d$, and source distance $\Delta z$, are both sufficiently small. A rough estimate of uncertainty for a given $d$ and $\Delta z$ can be obtained from the following equation describing the ionization current per unit mass of air as a function of position:

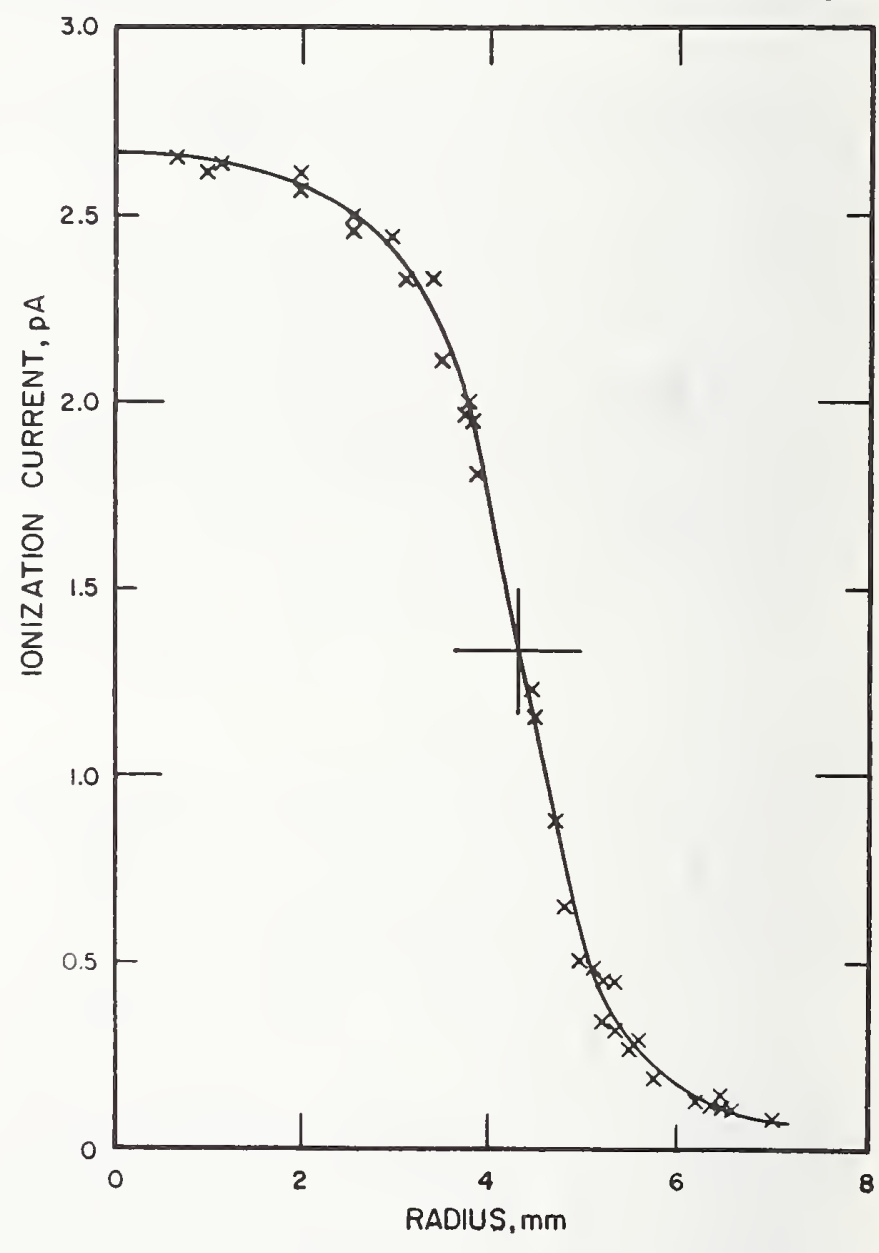

Fig. 9: Currents measured with the probe electrode across the face of SN D-402, plotted as a function of radius, measured from the center of the current distribution. The curve was drawn freehand. 


$$
\frac{d I}{d m}=K \cdot \log _{e} \frac{1+n^{2}-\mu^{2}+\sqrt{1+2\left(n^{2}-\mu^{2}\right)+\left(n^{2}+\mu^{2}\right)^{2}}}{2 n^{2}}
$$

where in terms of the coordinates of figure $1, \mu=r / R, n=\Delta z / R$, $r=\sqrt{x^{2}+y^{2}}$, and $k$ is a constant.

This equation was derived by the author assuming that the activity is spread uniformly over a circle of radius $R$ on the source surface, that the beta-particles are emitted isotropically from the source surface, that their paths are straight, and that energy deposition is uniform along these paths. The derivation is based on an $A / r^{2}$ solid angle approximation where $A$ is a plane area, and consequently current per unit solid angle becomes infinite as the distance approaches zero. If the current/volume is normalized to its value on the central axis of the source $(\mu=0)$, the normalized current is well behaved for all distances (that is, for all values of $n$ ).

Figure 10 is a plot of the normalized currents for several values of $n$. For each curve, the apparent radius $\vec{R}$ is the product of the true radius $R$ and the value of $\mu$ where the curve crosses the half-value line. For $n=1$, $\Delta \underline{z}=R$, and $\pi \bar{R}^{2}$ exceeds $\pi R^{2}$ by a factor of about 2. For $n=0.2$ (not shown) $\pi \bar{R}^{2}$ exceeds $\pi R^{2}$ by about $4 \%$, and for $n=0.1$, the difference is less than $1 \%$. In a typical case, $d=0.2 \mathrm{~mm}, \Delta z=0.12 \mathrm{~mm}, R=4 \mathrm{~mm}$, and $n=0.03$, for which $\pi \bar{R}^{2} / \pi R^{2}=1.001$.

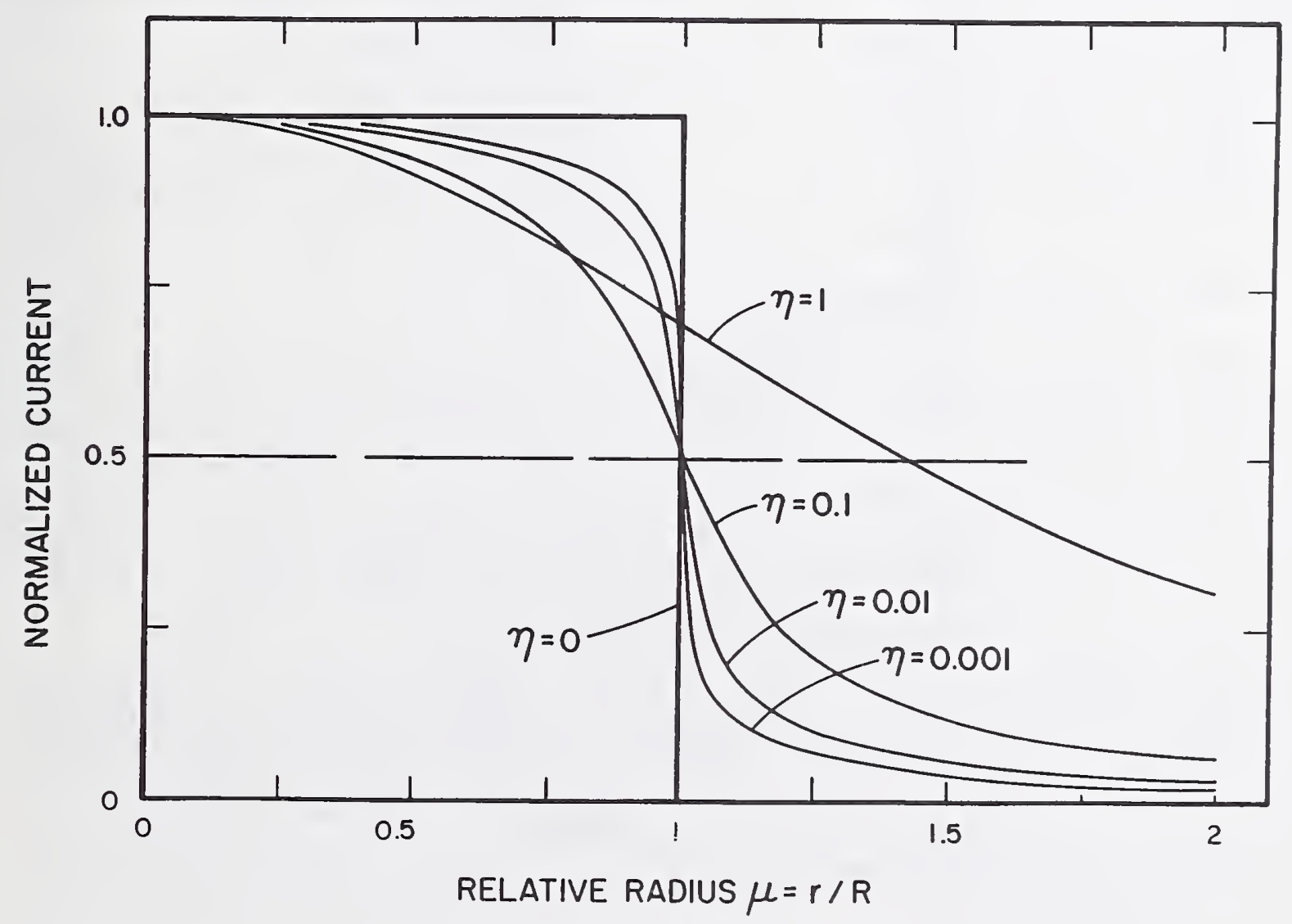

Fig. 10: Theoretical probe profiles for five different source distances, $n=\Delta z / R$. 
Figure 11 is a plot of probe ion current vs. radius for two applicators and matching source profiles calculated from $\overline{\mathrm{eq}}(8)$. The parameter $\Delta z$ was assigned the approximate value $0.1 \mathrm{~mm}$ in the calculation, and values of $\mathrm{R}=3.18 \mathrm{~mm}$ and $4.35 \mathrm{~mm}$ were read from the graph. All four curves have been normalized at the origin. Equation (8) is not an accurate description of either source profile, but the comparison with the NBS owned SN 0258 is consistent with the assumption that the activity in this source is spread uniformly over an area of $4.35-\mathrm{mm}$ radius. The small differences between theory and measurement appear to be easily explained. The differences near $r=R$ can be attributed to the finite size of the probe electrode. The differences at larger radii probably arise from the fact that the activity in SN 0258 lies below the applicator face, so that the elemental sources cannot be treated as isotropic at large angles. This will cause the real distribution to fall off more rapidly at large radii than the theoretical distribution. The activity in SN 157, in contrast, appears to be highly peaked at the center.

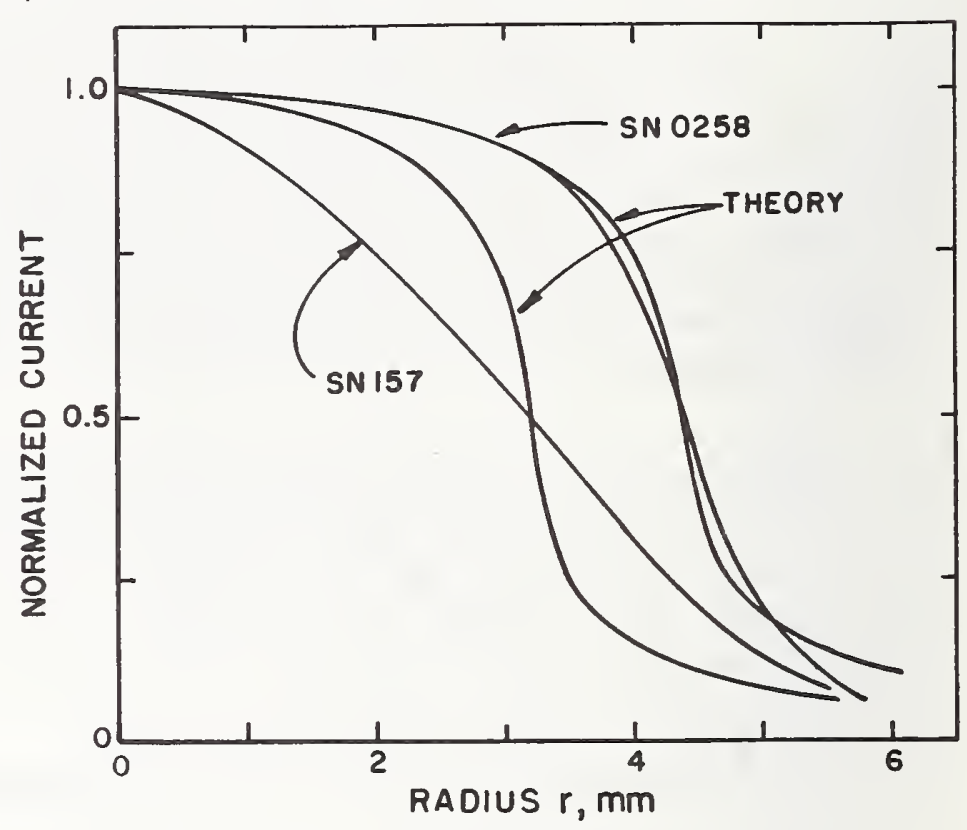

Fig. 11: Measured probe profiles of applicators SN 0258 and SN 157, in comparison with theoretical predictions for uniformly distributed sources.

\subsection{Qual ity assurance measurements:}

After measuring the source area, the probe electrode unit (fig. 6) should be replaced by the 30-mm electrode unit (fig. 3), and the source support structure should be retracted for a determination of $g_{0}$, the $d=0$ dial-gauge reading, for this electrode. The unknown source should be replaced by the NBS-owned SN 0258 applicator so that this $g_{0}$ determination can also serve as a quality assurance test. It is necessary to mount the applicator in a position that is independent of the vertical position of the source support structure, which is not reproducible. This can be done as shown in figure 12 . The SN 0258 plastic shield should be pushed as close to the source end as possible. The support structure should be retracted far enough so that the applicator handle rests on the bottom plate in figure 10 when it is centered in the hole as shown, but not far enough for the support structure itself to touch bottom. In this condition, small vertical motions of the support structure have no effect on the applicator position.

Extrapolation chamber current measurements should be made at each of the five g settings listed below. The current measurements should be multiplied by five correction factors, the four already described by eqs (4) to (7), as well as a decay correction factor: 


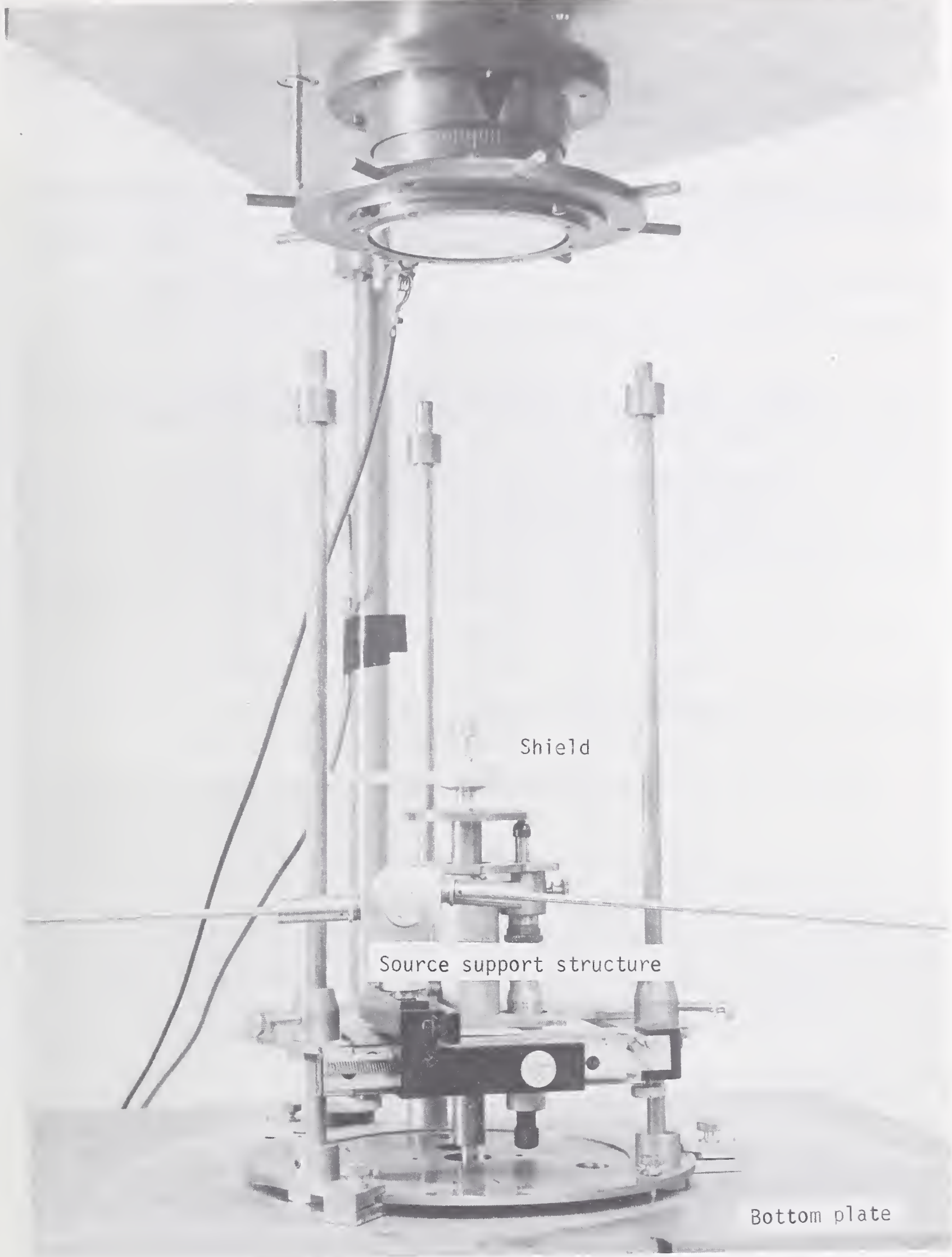

Fig. 12: Front view of extrapolation chamber (above), showing source support structure retracted for quality assurance measurements. NBS applicator SN 0258 is shown with its plastic shield moved towards the source. 


$$
f_{\text {decay }}=\exp (\lambda \Delta t)
$$

where $\Delta t$ is the time since the reference date of $1986 \mathrm{Jan} 1$, and $\lambda$ is the decay constant $\left(6.659 \times 10^{-5}\right.$ day-1 for $\left.905 r\right)$.

Finally, go should be determined by fitting the corrected currents to the equation:

$$
I=c_{0}+c_{1} g
$$

and calculating:

$$
g_{0}=-\frac{c_{0}}{c_{1}}
$$

The numbers computed for $I, C_{0}, C_{1}$, and $g_{0}$ should be recorded. The data

\begin{tabular}{|c|c|c|c|}
\hline $\begin{array}{c}\text { Captain's wheel } \\
\text { setting, g }\end{array}$ & Feb 20 & $\begin{array}{l}\text { urrent, } \mathrm{pA} \\
\text { Mar } 21\end{array}$ & Apr 3 \\
\hline 4.682 & 1.990 & 2.013 & 2.022 \\
\hline 4.485 & 3.939 & 3.969 & 3.974 \\
\hline 4.288 & 5.948 & 5.968 & 5.982 \\
\hline 4.092 & 7.951 & 7.977 & 7.961 \\
\hline 3.895 & 9.923 & 9.939 & 9.967 \\
\hline$c_{0}$ & 49.288 & 49.271 & 49.316 \\
\hline$c_{1}$ & -10.106 & -10.097 & -10.105 \\
\hline$g_{0}$ & 4.877 & 4.880 & 4.880 \\
\hline
\end{tabular}
listed below represents the first three sets of measurements made with the configuration shown in figure 12 .

The measured currents increased with time, but not enough to change the coefficients $c_{0}$ and $c_{1}$ or the dial-gauge-zero setting $g_{0}$ by more than $0.1 \%$. It is felt that all of these measurements were valid, but the reason for the current increase is unknown. These periodic checks will continue, and the results considered satisfactory unless $g_{0}$ changes by as much as $1 \%$. This would correspond to a change of about $0.1 \mathrm{~mm}$ in the dial-gauge-zero setting.

4.4 Current per unit air gap:

Applicator SN 0258 should now be replaced by the unknown source, and the source support structure raised until the source is near the extrapolation chamber high-voltage electrode. Then with $d=0.5 \mathrm{~mm}$, and $x=\bar{x}_{c}, y=\bar{y}_{c}$, the barrel micrometer reading $m_{0}$ for which $\Delta z=d / 2=0.25 \mathrm{~mm}$ should be found, by decreasing $\Delta z$ until the current drops rapidly. Current measurements are then made for the 5 different air gaps $d=0.5,1,1.5,2,2.5 \mathrm{~mm}$, with $z=d / 2+$ $0.01 \mathrm{~mm}$, for which the barrel micrometer readings are $m=m_{0}+d-0.49$. The current measurements should be corrected by the factors $f_{\text {temp }}$ and $f_{\text {recom }}$ from eqs (4) and (5). 
The corrected current per unit air gap at zero air gap, (I/d) 0 , comes from fitting the five corrected currents to the equation:

$$
I / d=(I / d)_{0}\left(1+\alpha d+\beta d^{2}\right)
$$

This extrapolation is only approximate for this poor-geometry determination. Sometimes a quadratic equation of this type fits the data very well and sometimes poorly. In general, $\alpha \approx-0.1 \mathrm{~mm}^{-1}$, and $\beta \approx 0.01 \mathrm{~mm}^{-2}$.

\section{Surface Absorbed-Dose Rates}

The average surface absorbed-dose rate in water comes from the Bragg-Gray formula:

$$
\dot{0}_{\text {water }}=\frac{33.7 \times 1.124}{1.197 \mathrm{~A}}(\mathrm{I} / \mathrm{d})_{0} \times \mathrm{k}_{\text {extrap }} \mathrm{k}_{\text {back }} \mathrm{k}_{\text {foil }} \mathrm{Gy} / \mathrm{s}
$$

where $A$ is the source area in $\mathrm{mm}^{2}$ and $(I / d)_{0}$ is the corrected current per unit air gap at zero air gap, in $\mathrm{nA} / \mathrm{mm}$. In the above equation, 33.7 is the average energy in joules, needed to produce one coulomb of ions of either sign in air, ${ }^{6} 1.124$ is the ratio of the average collision mass stopping power of water to that of air, 7 and 1.197 is the density of air at the reference temperature and pressure, in $\mathrm{kg} / \mathrm{m}^{3}$. The correction factors are:

$$
\begin{aligned}
k_{\text {extrap }}= & 0.98, \text { a correction for systematic errors in the extrapolation } \\
& \text { technique; }
\end{aligned}
$$
$k_{\text {back }}=1.010$, a correction for difference between backscatter from water and backscatter from TE plastic;

$k_{\text {foil }}=1.003$, a correction for foil attenuation in the extrapolation chamber entrance foil.

The $(I / d)_{0}$ ratio from eq (12) depends on the extrapolation path to a minor extent. For example, if the ratio $\Delta z / d$ had been maintained at 1 rather than at $1 / 2$, the measured $(\mathrm{I} / \mathrm{d})_{0}$ ratio would have been slightly smaller. Ideally, the ratio should be measured varying only $d$, with $\Delta z=0$ throughout. The closest one can come to this ideal situation is to extrapolate I/d to zero d for several fixed values of $\Delta z$ and then extrapolate the zero-d limits to zero $\Delta z$ independently, the procedure described at the end of section 2 . However, this increases the calibration time by a large factor and has consequently been replaced by the present techniques, where $\Delta z$ and $d$ are extrapolated to zero simultaneously. For applicator SN 0258, it was found that the ideal (I/d) 0 is $2 \%$ smaller than the value obtained with $\Delta z / d=1 / 2$. This is the origin of the correction factor kextrap

The backscatter factor was estimated from published formulas for backscatter probability as a function of atomic number and beta-particle energy. 8 Using the chemical formulation for the collecting electrode material, and the source spectrum measured with the silicon detector, figure 2 , the value for kback was obtained.

The foil attenuation correction factor, $k_{\text {foil }}=1.003$, was determined from measurements with extra thicknesses of $0.7 \mathrm{mg} / \mathrm{cm}^{2}$ aluminized foil. 
There is some uncertainty associated with each term of eq (13). Those determined by extrapolation-chamber ineasurements with the 30-mm-diameter collecting electrode, such as $(\mathrm{I} / \mathrm{d})_{0}$ and $\mathrm{k}_{\mathrm{foil}}$, have (relative) standard deviations of the order of $0.1 \%$. These are much smaller than the estimated uncertainties and are usually ignored. The estimated uncertainties are listed in the table below. Each is intended to be comparable to a (relative) standard deviation, in that the chance that the true value of the quantity lies within plus or minus the stated uncertainty is intended to be about 2 out of 3 (or, strictly speaking, there is a 2 out of 3 chance that the confidence interval generated in this fashion will cover the true unknown value of the quantity).

\begin{tabular}{lc} 
Absorbed-dose-rate uncertainties & $\begin{array}{c}\text { Relative } \\
\text { Uncertainty } \\
(\%)\end{array}$ \\
\hline Instrumental & 0.3 \\
Average energy per ion pair & 0.4 \\
Stopping-power ratio & 3 \\
Rate of change of current, (I/d) & 3 \\
Extrapolation correction, kextrap & 1 \\
Backscatter correction, k back & 1 \\
Attenuation correction, kfoil & $<0.1$ \\
Source surface area, A & 6 \\
\hline Combined uncertainty (quadratic sum) & 7.5 \\
Overall uncertainty (combined $\times 2)$ & 15
\end{tabular}

The instrumental uncertainties include voltmeter readings, capacitance measurements, and pressure and temperature determinations. The uncertainty in W/e comes directly from reference 5. The stopping-power-ratio uncertainty includes uncertainties in the stopping-powers themselves plus uncertainties in the beta-particle spectra. The uncertainty in (I/d) is an estimate of the reliability of a quadratic fit to an extrapolation curve with $\Delta z=d / 2$. The uncertainties in the three $k$ factors are all estimates based on the size of the corrections and on how carefully they were measured. The uncertainty in surface area is a (relative) standard deviation, based on repeated measurements for several sources, using the normal 2-mm grid.

When the uncertainties are combined in quadrature to obtain a combined uncertainty, the result is $\pm 7.5 \%$. This number is an approximate (relative) standard deviation. Doubling it gives an overall uncertainty of $\pm 15 \%$ which can be interpreted as having the approximate significance of a $95 \%$ confidence limit.

The surface area uncertainty is dominant in table 1 and is the only one that can be appreciably reduced at present. It can be reduced to about $1 \%$ by mapping a normal source with a $1-\mathrm{mm}$ grid, but this step is so much more timeconsuming that it is not offered as an NBS calibration service. In this case, nowever, the combined uncertainty would be about $\pm 4 \%$. This would lead to a stated overall uncertainty of $\pm 8 \%$ with the approximate significance of a $95 \%$ confidence limit. 
1. Calibrations and Related Services, National Bureau of Standards, Spec. Publ. 250, Gaithersbury, MD 20899 (1986).

2. J. S. Pruitt, "Calibration of Beta-Particle Ophthalmic Applicators at NBS," J. Res. Nat. Bur. Stand. (U.S.), 91, 165 (1986).

3. R. Loevinger and N. G. Trott, Int. J. Appl. Rad. Isotopes 17, 103 (1966).

4. J. Bohm, Physics in Med. and Biol. 21, 754 (1976).

5. J. S. Pruitt, Radiation Protection Dosimetry 11, 151 (1985).

6. ICRU Report 31, International Commission on Radiation Units and Measurements (Washington, D.C., 1979). The value of W/e cited comes from the value for dry air $(33.85 \mathrm{~J} / \mathrm{C})$, modified by a humidity factor for ambient air taken from Figure 5.14.

7. M. Berger and S. Seltzer, National Bureau of Standards Internal Report, NBSIR 82-2550A (1983); also as ICRU Report 37 (1984). The electron spectrum used was measured with a lithium-drifted silicon detector.

8. Tabata, Ito, and Okabe, Nucl. Instr. Methods 94, 509 (1971). 



\section{APPENDIX A. Examples from a data book}

The examples given are four pages from data book DB863, pages 133-136. These cover the calibrations of applicator SN176. The first three pages cover the area determination, using probe electrode $0.5 \mathrm{~A}$, and the fourth page covers the determination of (I/d) , using 30-mm-electrode 30F. There were no determinations of $g_{0}$, the $d=0$ dial-gauge reading. (The quantities called $\mathrm{g}$ and $g_{0}$ in this report have in the past been called $\ell$ and $\ell_{0}$ )

The values of $g_{0}$ used in the calibration of SN176 had been measured on 1983 Nov 11 for electrode $0.5 \mathrm{~A}\left(g_{0}=5.585\right)$, and on $1985 \mathrm{Apr} 1$ for electrode $30 F\left(g_{0}=4.888\right)$.

\section{The databook column headings and their meanings are:}

\section{time, $n$ :}

Real time on a 24-hour scale (i.e., 1436 is $2: 36$ p.m.). $n$ is a double number, $a-b$, where $a$ is the number of initial runs not included in the average and $b$ is the number averaged ( $i . e ., 1-5$ means there were six equip: measurements, but only the latter five were averaged).

A 1 isting of the apparatus. On page 133, for instance, the numbers stand for:

$0.5 \mathrm{~A}$ is the collecting electrode number

SN 176 is the applicator number

185325 is the NBS number of a Keithley 610C electrometer

$103.13 \mathrm{pF}$ is the measured capacitance on the scale used $\left(10^{-10}\right.$ coul)

168929 is the NBS number of a Fluke 412B high voltage power supply

189695 is the NBS number of the comparator on the DVM timer

$25 \mathrm{~s}$ is the comparator setting

183047 is the NBS number of a Digitec 266 DVM

$2 \mathrm{~V}$ is the DVM scale used

calc:

A listing of the quantities necessary to calculate currents from measured voltage changes. They are stored in the memory of an HP4IC calculator in bins:

81: d, the chamber electrode separation, in $\mathrm{mm}$

82, 83 and 84: $\alpha, \beta$, and $k_{s}$, constants needed for $f_{\text {atten }}$ and $f_{\text {scat }}$

85: A, either the active area of the source or the collecting electrode area, whichever is smaller, in $\mathrm{mm}^{2}$

86: $X$, the extrapolation chamber potential gradient, in $\mathrm{V} / \mathrm{mm}$

87: $\bar{I} / I(n A)$, a constant defining the units of the quantity $\bar{I}$

88: $\Delta t$, the number of days away from the reference date

89: $\lambda$, the source decay constant, in days-1

90: $\bar{C} / \bar{t}$, the ratio of capacitance to runtime. $\bar{C}=C \times 10^{12}$, $\bar{t}=t \times 10^{k}$. The exponent $k$ is usually chosen so that $\bar{c} / \bar{t}$ is

a number between unity and 10 .

91: $\mathrm{C}_{0}$, the DVM calibration correction factor 
$\underline{z, d}:$

Source distance and electrode separation, respectively, both in $\mathrm{mm}$. $\ell, \theta($ or $g, \theta)$ :

The extrapolation chamber coordinates needed to obtain the electrode separation $d_{e} \quad l$ (or $g$ ) is measured in tenths of an inch and $\theta$ in fractions of a revolution.

m,HV:

$m$ is the reading of the barrel micrometer used for fine adjustments of the vertical position of the applicator, in $\mathrm{mm}$. HV is the extrapolation chamber potential difference in volts.

$\underline{x, y}:$

The applicator horizontal and vertical coordinates on the microscope stage, in $\mathrm{mm}$.

$f_{T}, f_{D}:$

$\overline{\delta V}, \sigma_{1}$ :

The correction factors $f_{\text {temp }}$ and $f_{\text {decay }}$

If $\vec{V}$ is a voltage read from the DVM, $\bar{V}=V \times 10^{j}$, where $j$ is chosen to

el iminate decimal points in recording the data. $\overline{\delta V}$ is the average

change in $\bar{V}$ during a run. $\sigma_{1}$ is the standard deviation per run of this average.

$\overline{\mathrm{I}}, \overline{\mathrm{I}}_{\mathrm{B}}$ :

Normalized ion current and parasitic current, respectively. From the definitions of. $j$ and $k, \bar{I}=I \times 10^{j+12-k}$, and is usually recorded without decimal points.

${ }^{f_{S}, f_{R}}:$

The correction factors $f_{\text {scat }}$ and $f_{\text {recom }}$. 


\begin{tabular}{|c|c|c|c|c|c|c|c|c|c|c|}
\hline time /' & equip & calc & $z \quad d$ & $\& \theta$ & $m H V$ & $\begin{array}{ll}x & y\end{array}$ & $t_{T} / f_{D}$ & $\frac{\pi^{10}}{\delta V} \sigma_{1}$ & $\begin{array}{l}\times 10^{16} \\
\bar{I} / \bar{I}_{B}\end{array}$ & $f_{s} / 1$ \\
\hline 1040 & $0.5 \mathrm{~A}$ & 81: 0.2 & wes 0.2 & 5.510 .477 & $5.60+4$ & $124,2 \quad 35,0$ & 1.0211 & 534 & 6177 & .9981 \\
\hline \multirow[t]{9}{*}{$0=$} & SN $17 \mathrm{C}$ & $82 ! 0$ & & & - & & 1 & -2370 & -3787 & 1.0132 \\
\hline & 185325 & $83: 0$ & & & + & & & 560 & $c 247$ & \\
\hline & $103.13 \mathrm{pF}$ & $84: 0.0094$ & & & - & & & -2377 & -3748 & \\
\hline & 169929 & $85: 0.8$ & & & $t$ & & & 578 & 0279 & \\
\hline & $\mathrm{HV}$ & $8 c_{i} 20$ & & & - & & & -2374 & -3704 & \\
\hline & 189695 & 87: IET & & & + & & & 570 & 6264 & \\
\hline & $25 \mathrm{~s}$ & $98: 0$ & & & - & & & -2375 & -3723 & \\
\hline & 183047 & $89 . \angle .6 C B=5$ & & & + & & & 673 & 6262 & \\
\hline & $2 \sqrt{ }$ & $90: 4.1252$ & & & - & & & -2371 & -3709 & \\
\hline \multirow[t]{18}{*}{1054} & & $91: 0.9987$ & & & $5.60+$ & $119.2 \quad 32.0$ & & 177 & 11 & \\
\hline & & & & & $=$ & & & 172 & 720 & \\
\hline & & & & & $5.64+$ & 34.0 & & 476 & $\angle 839$ & \\
\hline & & & & & $=$ & & & -2539 & -3843 & \\
\hline & & & & & $5.65 \mathrm{t}$ & 114.229 .0 & & 94 & 11 & \\
\hline & & & & & - & & & 84 & 377 & \\
\hline & & & & & $5.29+$ & 31.0 & & 84 & 9 & \\
\hline & & & & & - & & & 80 & 338 & \\
\hline & & & & & $5.70+$ & 33.0 & & 84 & $2 !$ & \\
\hline & & & & & - & & & 74 & 326 & \\
\hline & & $\therefore$ & & & $5.69+$ & 35.0 & & 74 & 13 & \\
\hline & & & & & - & & & 18 & 293 & \\
\hline & - & & & & $5.76+$ & 37.0 & & 79 & 17 & \\
\hline & & & & & - & & & 21 & 309 & \\
\hline & & & & & $5.76+$ & 39.0 & & 78 & -2 & \\
\hline & & & & & - & & & 79 & 324 & \\
\hline & & & & & $5,79+$ & 41.0 & & 73 & -17 & \\
\hline & & & & & - & & & 81 & 318 & \\
\hline \multirow[t]{2}{*}{$112 !$} & & & & & $5.67+$ & $116,231.0$ & & 69 & 47 & \\
\hline & & & & & - & & & 47 & 239 & \\
\hline \multirow[t]{10}{*}{1300} & & & & & $5.66+$ & 33.0 & & 47 & 106 & \\
\hline & & & & & $=$ & & & -3 & 91 & - - \\
\hline & & & & - & $5.28+$ & 35.0 & & 12 & 155 & \\
\hline & & & & & $=$ & & & -61 & -101 & \\
\hline & & & & & $5.71+$ & 37.0 & & 38 & 140 & \\
\hline & & 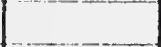 & & & - & & & -28 & 21 & 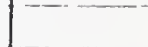 \\
\hline & & & & & $5.74+$ & $3 q, 0$ & & $<9$ & 70 & \\
\hline & & & & & - & & & $3 c$ & 217 & \\
\hline & & & & & $5.75+$ & 41.0 & & 74 & 2 & \\
\hline & & & & & - & & & 73 & 303 & \\
\hline \multirow[t]{8}{*}{1310} & & & & & $5.45+$ & 118.2310 & 1.0225 & -13 & 128 & \\
\hline & & & & & - & & 1 & -73 & -177 & \\
\hline & & & & & $5.63+$ & 33.0 & & 43 & 1693 & \\
\hline & & & & & $=$ & & & -752 & $-14<2$ & \\
\hline & & & & & $5.28+$ & 35.0 & & 512 & 4908 & \\
\hline & & & & & $=$ & & & -1792 & $-2<40$ & \\
\hline & & & & & $5,67+$ & 37,6 & & 155 & 2599 & \\
\hline & & & & & & & & -1065 & -1877 & \\
\hline
\end{tabular}




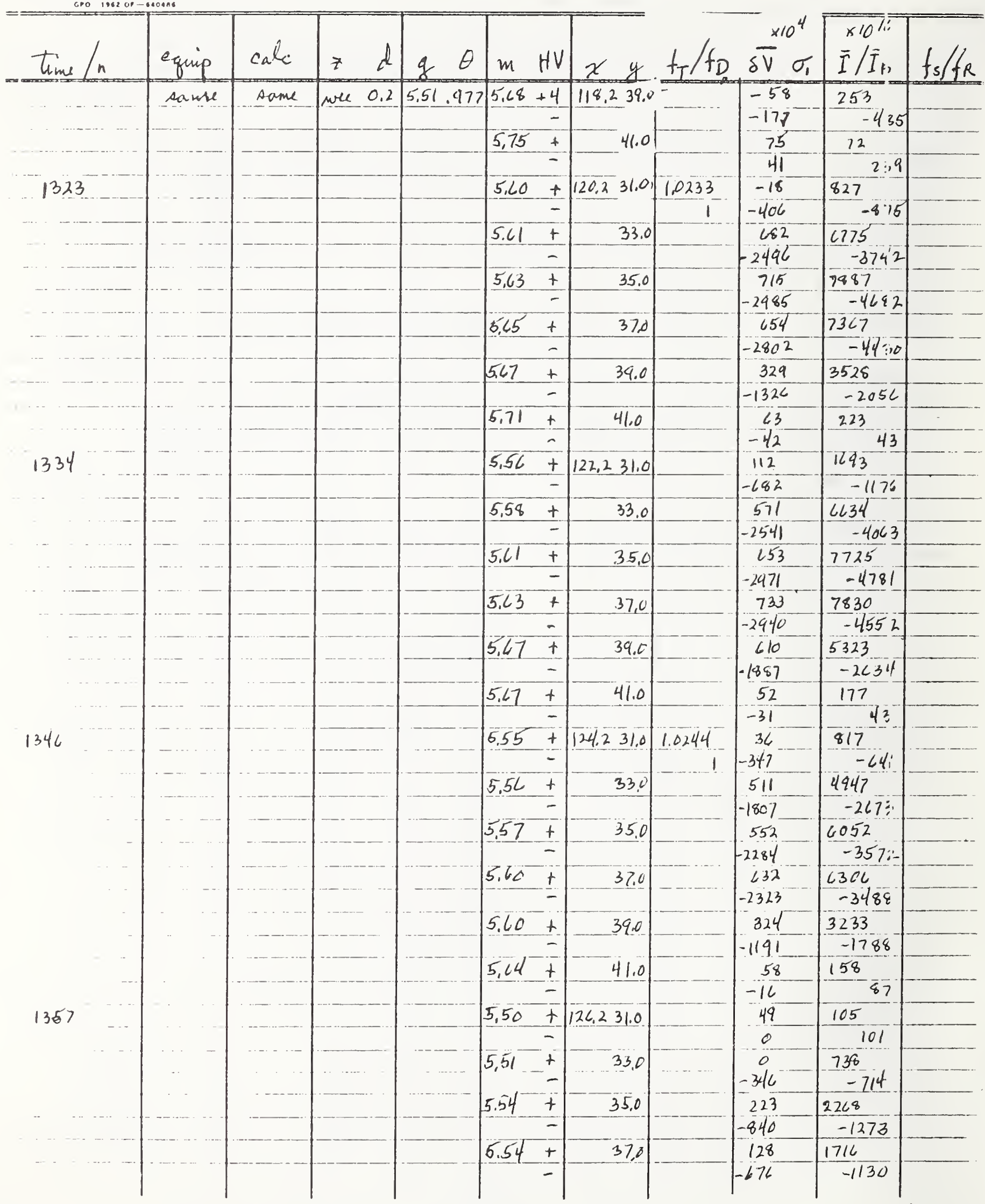


135

NBS 506-Analyals paper

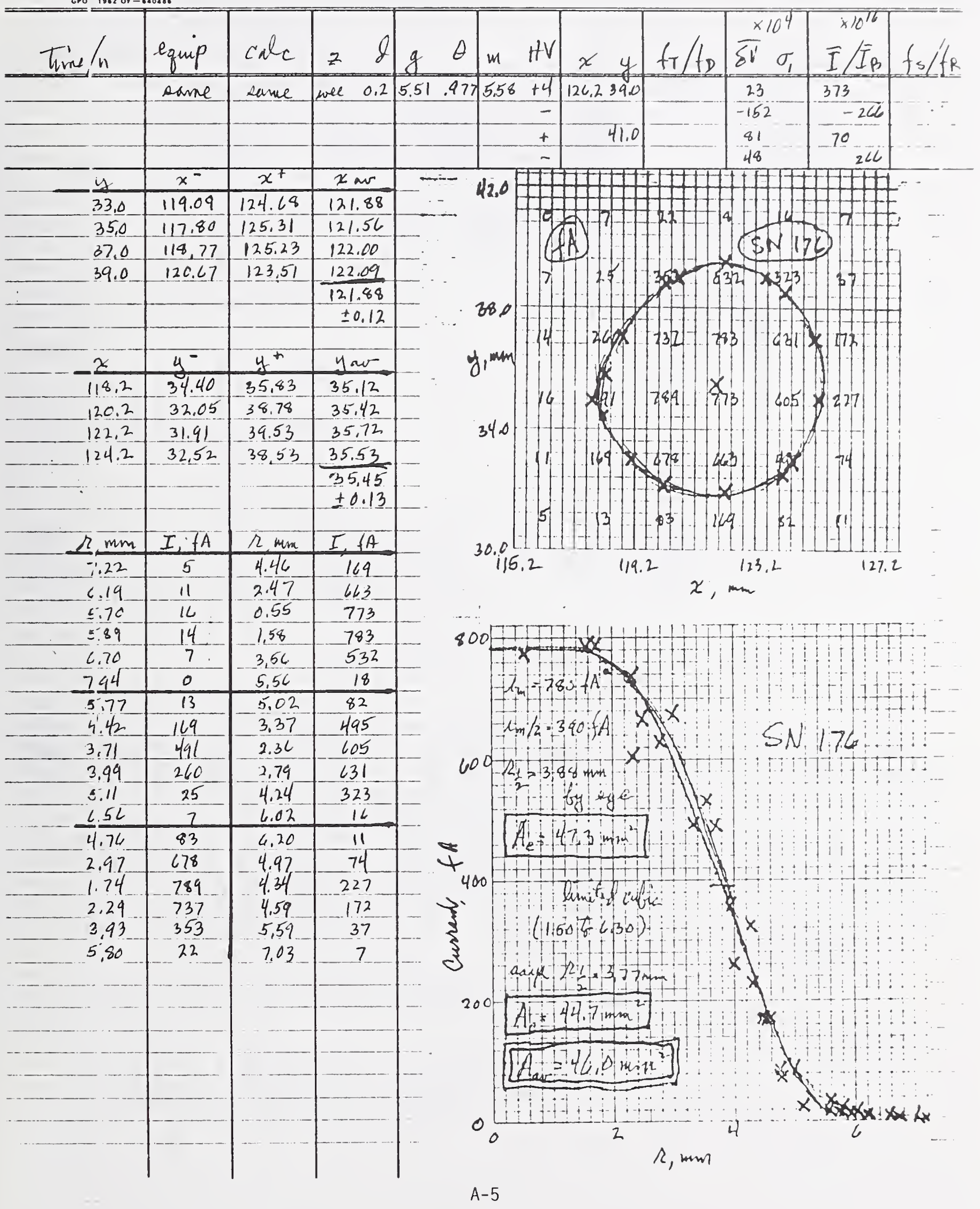




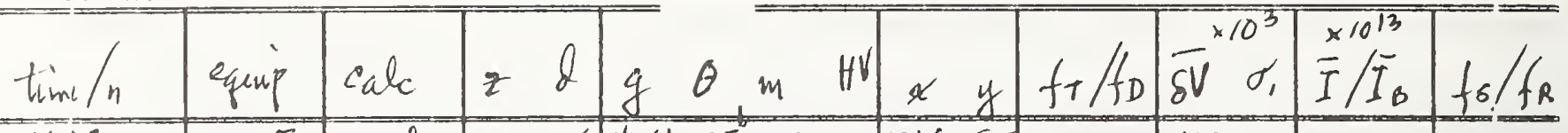
1619

$0-1$
$5 N \frac{176}{185325}$ $10147.2 \mathrm{pF} 84: 0$ 183047 $20 \mathrm{~V}$

1624 189695 $25 \mathrm{~S}$

87: $1 E 4$ $88: 0$ 89il.LEE-5 $90: 4.0589$ $41:$

\subsection{6} $1<47$

16.56

1703

1017

$1-5$

1026

1038

1046 1056

Claping 10 point: $D^{-}=\mid$

$.26 \quad .5$

$76 \quad 15$ 1.012 .0 1.262 .5

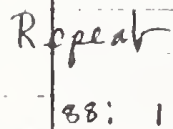

1.c) 2.0

1.26 2.5

$.76 \quad 1.5$

$\left|\begin{array}{|c|} \\ \cdots\end{array}\right|$ s1: 8L: 20

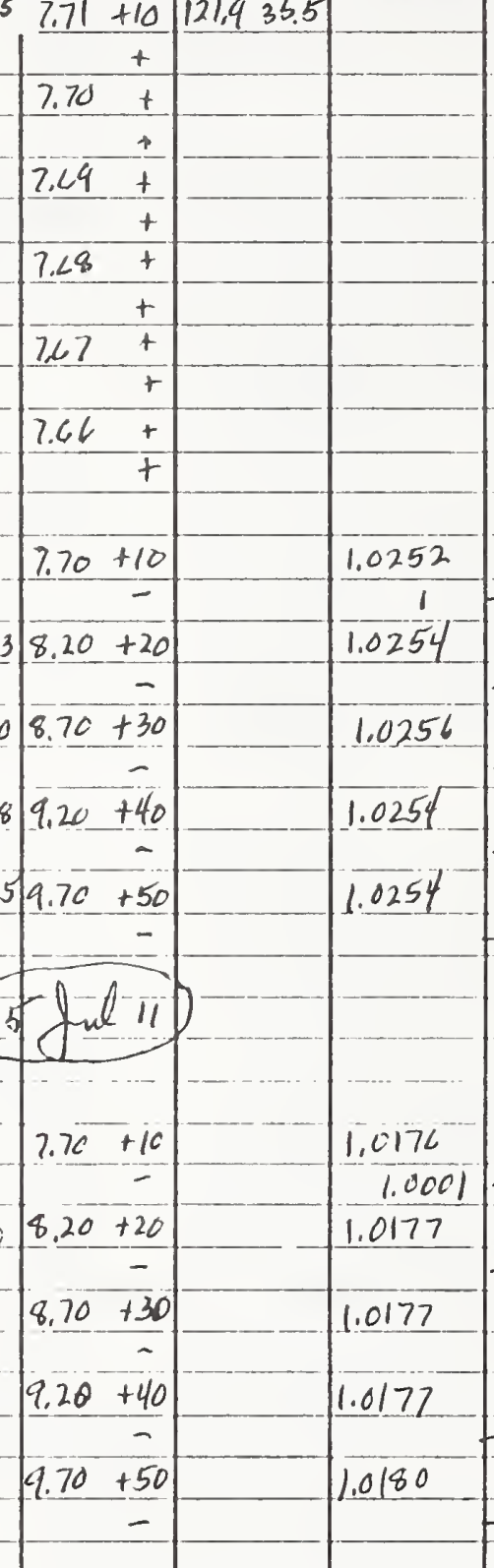

$\frac{617}{617}$

617 618

$.51 \quad 1.0 \quad 4.494 .023$ 4.297 .810 4.10 3.904 .385

-

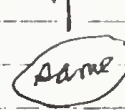

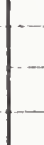

$-I \quad-$

$\frac{I}{d}=0.622 \phi\left(1-0.0718 d^{-}+0.0038 d^{2}\right) \cdot \frac{n A}{m m}$

$-$

$-14930$
618

418

416 609 609 601 4el

$m_{0}=769$

$m_{c}=7.19$

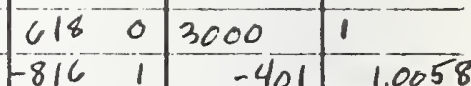

$1291 \quad 5797$

$-14830$

$1910-1$ $-2105^{\circ}$

2491

$-2 \angle 810$

3036 $-3216$

$\frac{-390}{8403}-1.0044$

10843

$-386 \quad 1.0075$

13132

$-379 \quad 1.0103$

(24) 3003

\begin{tabular}{lll}
-821 & 0 & -399 \\
\hline
\end{tabular}

$1299 \quad 0 \quad 5794$

192808410

$-2 \sqrt{21} \quad 0 \quad-391$

25120.10850

$-2702 \circ-384$

$3052 \circ 13131$

\begin{tabular}{ll}
-32380 & -377 \\
\hline
\end{tabular}

$-$ $1.124 \times 0.98 \times 1.003 \times 1.010 \times 0.0 .220$ $1.197 \times 46.0$
$D=0.43 G y$

A-6 
OG $8420 / 85$

Page 1 of 2

DB $863 / 133$

TFN 235324

1985 JUN 24

IJ. S. DEPARTMENT OF COMMERCE

NATIONAL BUREAU OF STANDARDS

GAITHERSBURG, MD 20899

REPORT OF CALIBRATION

${ }^{90} \mathrm{Sr}$ Beta-particle Source

Technical Operations Source No. 176 RS \#85-0879

Submitted by

Received at NBS on 1985 JUN 28

Calibration date 1985 JUL 10

Beta-particle sources are calibrated in terms of the absorbed-dose rate to water. Absorbed-dose $r$ ate is determined from current measurements with an extrapolation ionization chamber that has a tissue-equivalent-plastic collecting electrode. The water absorbed-dose rate is given by

$$
\delta=\frac{33.7 \times 1.124 \times B \times U}{1.197 \times A}\left(\frac{\Delta I}{\Delta d}\right)_{0} G y / s
$$

where $(\Delta I / \Delta d)_{0}$ is the rate of change of current (normalized to a reference temperature and pressure) with extrapolation chamber air-gap thickness as the thickness approaches zero, 33.7 is the mean energy expended per unit charge in air, 1.124 is the ratio of the mean mass stopping power of water to that of air, 1.197 is the density of air at the reference temperature and pressure $\left(22^{\circ} \mathrm{C}\right.$ and 1 standard atmosphere), B is a correction for reduced backscatter from the collecting electrode, $U$ is a correction for attenuation by the high-voltage electrode, and $A$ is an area. For calibrations at the surface of the source, $A$ is the active area of the source, defined as the area within the $50 \%$ isodose line at the source surface. The listed diameter is $2 \sqrt{A} / \pi$. 
For the source submitted, one calibration was inade, to determine the average absorbed-dose rate to water across the surface of the source. The active source area was determined by inapping the relative dose rate across the source surface with a $1-\mathrm{mm}$ diameter collecting electrode. The rate of change of current with air-gap thickness was measured with a $28-1 \mathrm{~m}$ dianeter conducting plastic collecting electrode.

The water absorbed-dose rate at the surface of the source, averaged over the active area of the source, is given in the table in SI units (grays per second) and in special units ( $r$ ads per second).

This measurement has been assigned an uncertainty of $\pm 15 \%$, which has the approximate significance of a $95 \%$ confidence 1 imit.

Information on the technical aspects of this report can be obtained from J. S. Pruitt, Radiation Physics C206, National Bureau of Standards, Gaithersburg, Maryland 208799. (301) 975-5587.

Callibration performed by J. S. Pruitt fSP

Report approved by R. Loevinger $\mathrm{R}$

For the Director

by

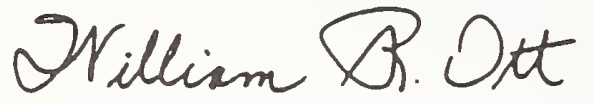

William R. Ott

Chief, Radiation Physics Division

Center for Radiation Research

National Measurement Laboratory

\begin{tabular}{|c|c|c|c|c|c|c|}
\hline Source & $\begin{array}{c}\text { Dist ance } \\
(\mathrm{mm})\end{array}$ & $\begin{array}{l}\text { Area } \\
\text { A } \\
\left(\mathrm{mm}^{2}\right)\end{array}$ & $\begin{array}{c}\text { Diameter } \\
(\mathrm{mm})\end{array}$ & $\begin{array}{c}\text { Correction } \\
B\end{array}$ & $\underset{U}{f \text { actors }}$ & $\begin{array}{c}\text { Water } \\
\text { Absorbed-dose rate } \\
(G y / s)(r a d / s)\end{array}$ \\
\hline 176 & 0 & 46 & 7.6 & 1.010 & 1.003 & 0.43 \\
\hline
\end{tabular}


SHEET (See in struction s) REPORT NO.

NBS/SP-250/9

4. TITLE AND SUBTITLE

NBS Measurement Services:

Calibration of Beta-Particle-Emitting Ophthalmic Applicators

5. AUTHOR(S)

John S. Pruitt

6. PERFORMING ORGANIZATION (If joint or other than NBS, see instructions)

7. Contract/Grant No.

NATIONAL BUREAU OF STANDARDS

U.S. DEPARTMENT OF COMMERCE

GAITHERSBURG, MD 20899

8. Type of Report \& Period Covered

Final

9. SPONSORING ORGANIZATION NAME AND COMPLETE ADDRESS (Street, City, State. ZIP)

Same as item 6.

10. SUPPLEMENTARY NOTES

Library of Congress Catalog Card Number 87-619844

Document describes a computer program; SF-185, FIPS Software Summary, is attached.

11. ABSTRACT

This service provides calibrations for $90 \mathrm{Sr}+90 \mathrm{y}$ beta particle ophthalmic applicators. The calibration determines the average surface absorbed-dose rate to water over the active area of the applicator. The technique used is to measure current per unit mass of air at the active surface with an extrapolation ionization chamber, and to convert this into absorbed-dose rate with Bragg-Gray cavity ionization theory. The extrapolation chamber measurements are made in three parts. In the first part, a $1 \mathrm{~mm}$ diameter probe electrode is used to map the relative dose rate across the source surface. and to determine the active area. In the serond part, the probe electrode is replaced by a $30 \mathrm{~mm}$ diameter electrode, and the test applicator is replaced by an NBS-owned applicator for quality assurance measurements. In the third part, the $30 \mathrm{~mm}$ electrode is used with the test applicator to determine the extrapolation curve slope at the source surface. The ratio of this slope to the source area, divided by the air density, yields current per unit air mass. The transformation to absorbed-dose rate is described. The component uncertainties are listed and are shown to yield a total uncertainty of $\pm 15 \%$, with the approximate significance of a $95 \%$ confidence limit. Data book measurements and $\exists$ calibration report are given for one particular applicator.

12. KEY WORDS (Six to twelve entries; alphabetical order: capitalize only proper names; and separate key words by semicolons) absorbed dose rate; calibration service; extrapolation chamber; ophthalmic applicator; quality assurance measurements; surface dose rate.

13. AVAILABILITY

X Unlimited

For Official Distribution. Do Not Release to NTIS

* Order From Superintendent of Documents, U.S. Government Printing Office, Washington, DC 20402.

[] Order From National Technical Information Service (NTIS), Springfield, VA 22161
14. NO. OF PRINTED PAGES

\section{6}

15. Price 





\section{PUBLICATIONS IN THE SP 250 SERIES FROM THE CENTER FOR RADIATION RESEARCH}

SP 250-1 NBS Measurement Services:

Spectral Radi ance Calibrations

J.H. Walker, R.D. Saunders, and A.T. Hattenburg

SP 250-2 NBS Measurement Services:

Far Ultraviolet Detector St andards

L.R. Canfield and N. Swanson

SP 250-3 NBS Measurement Services:

Radiometric Standards in the Vacuum Ultraviolet J.Z. Klose, J.M. Bridges, and W.R. Ott

SP 250-4 NBS Measurement Services:

Fricke Dosimetry in High-

Energy Electron Beams

C.G. Soares, E.L. Bright and M. Ehrlich

SP 250-5 NBS Measurement Services:

Alpha-Particle Calibrations

J.M.R. Hutchinson

SP 250-6 NBS Measurement Services:

Regular Spectral Transmittance

K.L. Eckerle, J.J. Hsia, K.D. Mielenz, and V.R. Weidner

SP 250-7 NBS Measurement Services:

Radiance Temperature Calibrations

W.R. Waters, J.H. Walker, and A.T. Hattenburg

SP 250-8 NBS Measurement Services:

Spectral Reflect ance

V.R. Weidner and J.J. Hsia

SP 250-9 NBS Measurement Services:

Calibration of Beta-Particle-Emitting

Ophthalmic Applicators

J.S. Pruitt

SP 250-10 NBS Measurement Services:

Radioactivity Calibrations with the " $4 \pi$ "

Gamma Ionization Chamber, and Other

Radioactivity Calibration Capabilities

J.M. Calhoun

SP 250-11 NBS Measurement Services:

Dosimetry for High-Dose Applications

J.C. Humphreys, D. Hocken, and W.L. MCLaugh lin
SP 250-12 .NBS Measurement Services:

Neutron Personnel Dosimetry

R.B. Schwartz

SP 250-13 NBS Measurement Services:

Act ivation Foil Irradiation

with Californium Fission Sources

G.P. Lamaze and J.A. Grund 1

SP 250-14 NBS Measurement Services:

Activation Foil Irradiation by Reactor

Cavity Fission Sources

G.P. Lamaze and J.A. Grund 1

SP 250-15 NBS Measurement Services:

Photometric Calibrations

R.L. Booker and D.A. McSparron

SP 250-16 NBS Measurement Services:

Calibration of X-Ray and Gamma-Ray

Measuring Instruments

P.J. Lamperti, T.P. Loftus, and R. Loevinger

SP 250-17 NBS Measurement Services:

The NBS Photodetector Spectral Response

Calibration Transfer Program

E.F. Zalewski

SP 250-18 NBS Measurement Services:

Neutron Source Strength Calibrations

E.D. McGarry and E.W. Boswe 11

SP 250-19 NBS Measurement Services:

Calibration of Gamma-Ray-Emitting

Brachyther apy Sources

J.T. Weaver, T.P. Loftus, and R. Loevinger

SP 250-20 NBS Measurement Services:

Spectral Irradiance Calibrations

J.H. Walker, R.D. Saunders, J.K. Jackson, and D.A. McSparron

SP 250-21 NBS Measurement Services:

Calibration of Beta-Particle

Radiation Instrument ation and Sources

J.S. Pruitt, C.G. Soares, and M. Ehrlich 
U.S. Department of Commerce

National Bureau of Standards

Gaithersburg, MD 20899

Official Business

Penalty for Private Use $\$ 300$ 